\title{
A Role for Action-Potential Activity in the Development of Neuronal Connections in the Kitten Retinogeniculate Pathway
}

\author{
Mark W. Dubin, Louisa A. Stark, and Steven M. Archer ${ }^{1}$ \\ Department of MCD Biology, University of Colorado, Boulder, Colorado 80309
}

\begin{abstract}
The role of action potentials in the development of proper synaptic connections in the mammalian CNS was studied in the kitten retinogeniculate pathway. Our basic finding is that there is improper segregation of retinal inputs onto LGN cells after prolonged retinal action-potential blockade. Retinal ganglion cell firing was silenced from birth by repeated monocular injections of TTX. The resulting ganglion cell connections in the LGN were studied electrophysiologically after the action-potential blockade was ended. Most cells in the deprived LGN layers received excitatory input from both $\mathrm{ON}$-center and OFF-center type ganglion cells, whereas LGN cells normally receive inputs only from ON-center or OFF-center ganglion cells, but not from both types. Improper segregation of ON and OFF inputs has never been reported after other types of visual deprivation that do not block ganglion cell activity. Control experiments showed that receptive fields in the nondeprived LGN layers were normal, that ganglion cell responses remained normal, and that there was no obvious ganglion cell loss. We also showed that individual LGN cells with $O N$ and OFF excitatory inputs were not present in normal neonatal kittens.
\end{abstract}

Two other types of improper input segregation in response to action-potential blockade were also found in the deprived LGN layers. (1) A greater than normal number of LGN cells received both $\mathrm{X}$ - and Y-type ganglion cell input. (2) Almost half of the cells at LGN layer borders were excited binocularly.

Recovery of LGN normality was rapid and complete after blockade that lasted for only 3 weeks from birth, but little recovery was seen after about 11 weeks of blockade. The susceptibility to action-potential blockade decreased during the first 3 postnatal weeks.

These findings may result from axon-terminal sprouting or from the failure of axon terminals to retract. The results are consistent with the idea that normally synchronous activity of neighboring ganglion cells of like center-type may be used in the refinement of retinogeniculate synaptic connections.

During CNS development, neurons must differentiate, elongate dendrites, and form proper synaplic connections. The results of these activities are very specific, both in terms of where axon tracts project and the synapses that are made. Many factors

Received June 27, 1985; revised Aug. 29, 1985; accepted Aug. 29, 1985.

Supported by Grants 1 R01 EY-04629 from the NIH, BNS76-00506 and BNS7914110 from the NSF, 1-798 from the March of Dimes, and in part by RR 0701319 awarded by the BRSG program of NIH-DRR, and Post-doctoral Fellowships 7F32 EY-05442 to S.M.A. and 5F32 EY-05554 to Elizabeth Pulos from the NIH. We wish to thank Dr. Pulos, Catherine Auerbach, Stephanie Vamos, Lynette Bangs, Melanie Adcock, Kristen Johnson, and Carroll Loyer for their assistance; David Mastronarde for many helpful conversations and much good advice; and Drs. Arthur Weber and Michael Stryker for careful reading of drafts of the manuscript. Toxiferine was graciously provided by Hoffman-La Roche Inc.

Correspondence should be addressed to Prof. Dubin, Box 347-MCD Biology, University of Colorado, Boulder, CO 80309-0347.

I Present address: 702 Rotary Circle, Indiana University Medical Center, Indianapolis, IN 46223.

Copyright (C) 1986 Society for Neuroscience $0270-6474 / 86 / 041021-16 \$ 02.00 / 0$ act in concert to bring this about. One of these, action-potential activity itself, is the focus of this report. The system studied is the retinogeniculate projection of neonatal kittens reared with the action potentials of one eye totally blocked by intraocular tetrodotoxin (TTX) injections. This system is appropriate for such studies because it is one in which there is significant postnatal synaptic development.

Initial proposals that neural activity might play a role in determining connections in the mammalian CNS were mainly theoretical (Brindley, 1969; Griffith, 1966; Hebb, 1949; see reviews in Levy et al., 1985). The vast body of work on visual system development and the effects of visual deprivation lent credence to this concept (see reviews by Movshon and van Sluyters, 1981; Sherman and Spear, 1982). Support also came from experiments in the PNS. For example, abolition of impulse activity retards reduction from polyneuronal to mononeuronal innervation of certain muscle fibers (Benoit and Changeux, 1978; Harris, 1981; Thompson et al., 1979). Also, the reduction of excess innervation in autonomic ganglia has been suggested as possibly being activity-related (Purves, 1983; Purves and Lichtman, 1980).

Recently, our work (Archer et al., 1982) and that of others (see review by Fawcett and O'Leary, 1985) has provided experimental evidence that action-potential activity in the CNS is important in the determination of proper synaptic connectivity. For example, activity can play a role in determining the extent and position of axon terminals. This has been shown in goldfish, where regenerating retinotectal axons do not form proper size terminal fields or ocular dominance patches if the axons are silenced during regeneration (Boss and Schmidt, 1984; Meyer, 1982, 1983; Schmidt and Edwards, 1983). Action-potential activity has also been related to the formation of tectal ocular dominance stripes in frogs with a "third eye" graft (ConstantinePaton, 1983; Constantine-Paton and Law, 1978; ConstantinePaton and Reh, 1983; Reh and Constantine-Paton, 1985). It has been shown that the development of ocular dominance columns in the kitten cortex depends on synchronous activity in geniculocortical inputs (Stryker, in press; Stryker and Harris, in press). Synchronous activity has also been implicated in the proper development of connections made between nucleus isthmi and tectum in the frog (Udin, 1983), and Sanes and Constantine-Paton $(1983,1985)$ have suggested a role for synchronous firing in the determination of connections in the auditory system of neonatal mice. Dependence on activity has also been demonstrated in the normal developmental loss of incorrect axonal projections. In the neonatal rat, selective elimination of ganglion cells that inappropriately terminate in the ipsilateral superior colliculus does not occur when ganglion cell action potentials are blocked (Fawcett et al., 1984).

It is now clear that mechanisms involving action-potential activity are important in CNS development. In this work we show that proper segregation of ganglion cell axon terminals onto their target cells in the LGN requires the presence of ac- 

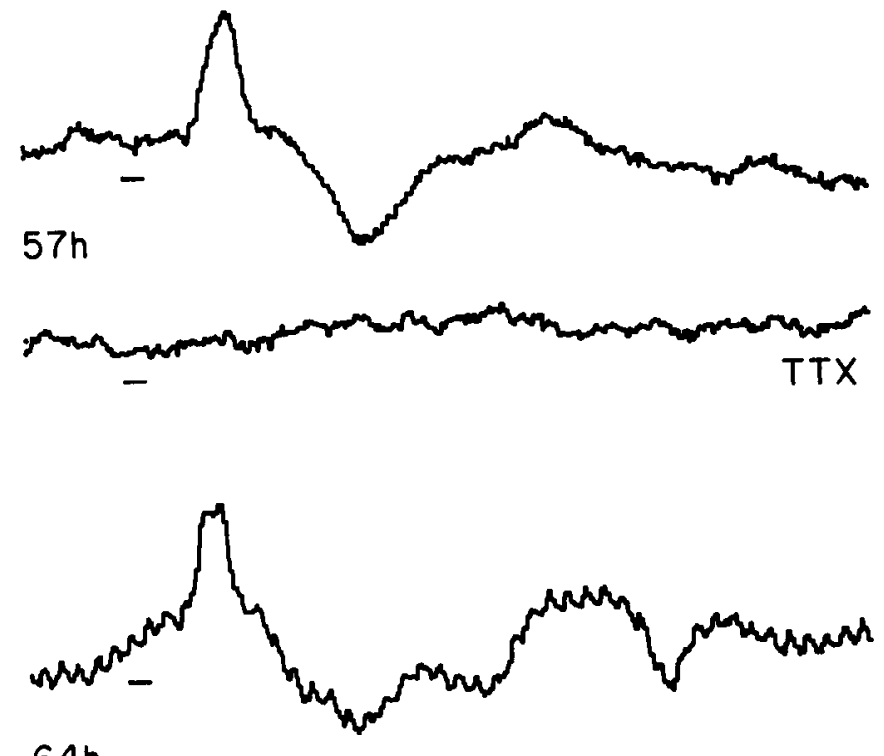

$64 h$
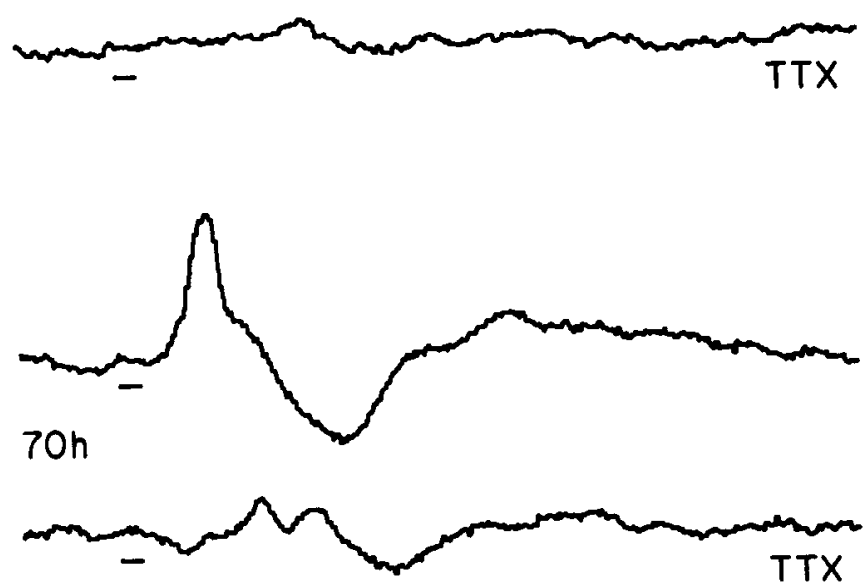

Figure 1. Recovery from action-potential blockade as assessed with the VEP. Each trace is the analog averaged VEP in response to 100 flashes (except 50 flashes for the $64 \mathrm{hr}$ normal); all traces are shown at the same scale. The bar under each trace indicates the time of the 20 msec flash. The upper trace of each pair is the response of the uninjected eye, the lower trace the response of the TTX-injected eye. The injected eye received an approximately maximal dose of TTX. At $57 \mathrm{hr}$ (upper traces), a VEP was elicited only through the uninjected eye, whereas by $70 \mathrm{hr}$ postinjection (lower traces), there was a clear response via the injected eye. A small response is present at $64 \mathrm{hr}$ postinjection via the injected eye. The noise on the middle, normal trace is $60 \mathrm{~Hz}$ contamination.

tivity in those terminals. Lack of activity leads to abnormal receptive field types in the LGN that are different from those reported to occur in response to visual deprivation that does not silence action potentials.

\section{Materials and Methods}

Kittens were born and raised in our departmental animal colony. In reporting their ages, the day of birth is taken as day zero.

\section{TTX intraocular injections}

Action potentials were silenced with the sodium channel blocker TTX (Evans, 1972). Kittens were anesthetized with $1-3 \%$ halothane during the TTX injection procedure. Injections were made into the left eye using a 33 gauge sterile needle that was soldered into 26 gauge stainless steel tubing, with $4 \mathrm{~mm}$ of the needle protruding. The injection needle was manipulated by being held at the 26 gauge portion in a fine-tipped needle holder, and was attached by flexible Silastic tubing to a $25 \mu \mathrm{l}$
Unimetrics syringe. The needle was inserted $4 \mathrm{~mm}$ into the vitreous humor through closely adjacent sites at the pars plana. Each injection was visualized through a binocular operating microscope. Prior to the first injection the lateral canthus was extended with a small skin cul. The conjunctiva was cleared over the injection site before each injection, and the globe was stabilized with a scleral fixation hook while being penetrated. Topical antibiotics were applied to the eye after each injection. Even after multiple injections, optics usually remained undistorted, and retinal whole-mounts showed no obvious damage except occasionally very near the injection site. TTX-blocked eyes also had a grossly normal electroretinogram response.

TTX (Sankyo, $1 \mathrm{mg}$ with $5 \mathrm{mg}$ citrate buffer) was made up to $1 \mu \mathrm{g} /$ $\mu$ l with sterile water, to which sterile methylene blue was added to be able to easily notice any injection backflow. In an early series of experiments, using various TTX doses, we calculated that TTX leaves the eye with a half-time of about $7 \mathrm{hr}$ and ceases to block activity when its concentration in the eye falls below about $0.1 \mu \mathrm{M}$. The TTX that leaves via the circulatory system can cause systemic effects, and if allowed to become too high, the whole-body dose can kill the kitten. This limited the maximum amount of TTX that could be injected into the eye to a dose that blocked activity for $21 / 2-3 \mathrm{~d}$.

The duration and completeness of TTX blockade of ganglion cell activity was initially assessed by short-term experiments in which extensive retinal and LGN single-unit recordings were made after injection. The time course of blockade was then related to indicators of visual system activity that could be used in long-term experiments. To do this we determined the relationship between the recovery of ganglion cell activity and recovery of the cortical visual evoked potential (VEP). The VEP was recorded from a silver wire implanted through the skull touching the dura over the visual cortex, with an indifferent electrode in the head skin and a ground electrode in the neck skin. We found that at the time during recovery from TTX, when only very few ganglion cells could be recorded in response to visual stimulation, and no spontaneous activity was present, a VEP to a $20 \mathrm{msec}$ flash could readily be recorded. That is, VEP recovery is a very sensitive measure of recovery of retinal ganglion cell activity. Analog averaging was used to improve the VEP signal-to-noise ratio and to see the earliest stages of recovery. Typical results of VEP monitoring are shown in Figure 1. Both eyes were stimulated separately with a light-emitting diode cemented to a contact lens, at various times after a near-maximal intraocular TTX injection. Note that a VEP could be elicited through the injected eye about 64-70 hr after the TTX injection. Occasionally, the first such VEP recorded was unexpectedly larger than the VEP elicited through the normal eye.

Using the VEP we determined that injections of 2.5-11 $\mu \mathrm{g}$ of TTX, depending on age and weight of the animal, effectively blocked ganglion cell action potentials for at least $2^{1 / 2} \mathrm{~d}$. Normally, kittens were first injected at age 1 or $2 \mathrm{~d}$, and injections were then continued at $2 \mathrm{~d}$ intervals. (Unless noted, injection series started prior to $3 \mathrm{~d}$ of age are taken to have started at birth in the quantitative presentations of the data.) The dosage schedule was as follows: first injection, $2.5 \mu \mathrm{g}$ TTX $(2 \mu \mathrm{g}$ if weight $<100 \mathrm{gm}, 3 \mu \mathrm{g}$ if $=120-140 \mathrm{gm}, 3.5 \mu \mathrm{g}$ if weight $>140$ $\mathrm{gm}$ ); each subsequent injection $0.5 \mu \mathrm{g}$ greater until $5 \mu \mathrm{g}$ injections reached; then, $5 \mu \mathrm{g}$ continued until animal was 6 weeks old or $600 \mathrm{gm}$, whichever came first; then, increased $1 \mu \mathrm{g}$ for each $100 \mathrm{gm}$ of weight or week of age, up to $10 \mu \mathrm{g}$ at 10 weeks or $1000 \mathrm{gm}$; increase to $11 \mu \mathrm{g}$ at $1075 \mathrm{gm}$, with no increase thereafter to age 20 weeks.

Once the dosage schedule had been determined and verified in many animals using the VEP, we routinely monitored injection effectiveness by noting the presence or absence of a pupillary response to an intense light shone into each eye. A TTX-blocked eye would not respond, while the pupil of the uninjected eye always contracted. We determined that the pupillary response was not as sensitive a measure of recovery from action-potential blockade as was the VEP. Usually, a small VEP could be seen about $10 \mathrm{hr}$ prior to the pupillary response. However, even at that time, ganglion cells were not firing spontaneously and gave only a response of one or two spikes to a bright stimulus.

\section{Electrophysiological techniques}

Animals were set up for single-unit recording using standard techniques modified for young kittens (Dubin and Cleland, 1977; Rusoff and Dubin, 1977). Kittens were initially anesthetized with halothane, which was continued for all surgical procedures. After the placement of a venous arm cannula, a tracheal cannula, and EKG electrodes, they were paralyzed with gallamine triethiodide (Flaxedil), which was maintained at 
$10 \mathrm{mg} / \mathrm{kg} \cdot \mathrm{hr}$, and then continuously respired with $70 \% \mathrm{~N}_{2} \mathrm{O}$ and $30 \%$ $\mathrm{O}_{2}$. If necessary for stability during recording sessions, Flaxedil was supplemented with $1 \mathrm{mg} / \mathrm{kg} \cdot \mathrm{hr}$ toxiferine (Hoffmann-La Roche). The skull was held in stereotaxic alignment (Norman, 1974) by use of a bolt cemented to it. All wounds and pressure points were infiltrated with $5 \%$ Xylocaine paste. Stable heart rate and synchronized EEG were used as measures of adequate anesthesia. End-tidal $\mathrm{CO}_{2}$ was monitored with a Beckman LB-2 gas analyzer and kept at about $4 \%$. Body temperature was kept at about $38^{\circ} \mathrm{C}$ with a thermostatically controlled blanket. Corneas were protected from dehydration with zero-power contact lenses. Pupils were dilated and accommodation paralyzed with $1 \%$ atropine sulfate and $2.5 \%$ neosynephrine drops. Fyes were usually within $0-2$ diopters of emmetropic, and corrective lenses were not normally used.

The LGN was approached stereotaxically from above through a craniotomy. In experiments in which the medial interlaminar nucleus (MIN) was recorded, an initial electrode track in the LGN was followed by a series of tracks increasingly more medial to the first one. In this way, a progression of retinotopic positions toward the vertical midline was noted from track to track. We determined that the MIN was finally reached when we recorded visual field positions once again far lateral to the midline (Sanderson, 1971). For intraocular recording of ganglion cells, the eye was sewn to a stabilizing ring and the electrode was inserted through a hole in the sclera (Cleland et al., 1971). All recording was extracellular, using tungsten-in-glass microelectrodes (Levick, 1972).

Spikes were displayed on an oscilloscope and were fed to an audio monitor. Schmitt-trigger pulses derived from the spikes were input to a computer for construction of peri-stimulus-time-histograms (PSTHs). The computer was also used as an analog averager. To guarantee that only a single isolated spike was being triggered on, PSTHs were only built for spikes at least $3 \times$ the noise level. In later experiments, this judgment was aided by the use of a delay line that allowed visualization of the entire spike waveform.

Computer-controlled spot stimuli were presented by a Kodak or a Leitz Prado projector; hand-held targets were also used as stimuli. Most PSTHs were constructed using spot stimuli about $1-2 \log$ units above threshold, against a background of $8 \mathrm{~cd} / \mathrm{m}^{2}$. Most cells were tested with a range of spot sizes, $0.5^{\circ}-2.5^{\circ}$ in diameter. Nondeprived cells were characterized as X- or Y-type using a standard set of tests (Cleland et al., 1971; Dubin and Cleland, 1977), which were occasionally augmented with a counterphased grating test (Hochstein and Shapley, 1976) generated on a display oscilloscope.

\section{Histology}

Brains were prepared for light microscopy by perfusion of deeply barbiturate-anesthetized animals with neutral buffered formalin. Sections of unembedded tissue were cut on a Vibratome; paraffin-embedded sections were cut with a rotary microtome. Sections were stained with cresyl violet. Eyes were removed after deep anesthesia was achieved and before perfusion. Retinas were prepared for study by the flat-mount technique of Hughes (1975), which minimizes shrinkage, and were stained with cresyl violet. Cell size measurements were done planimetrically, directly from the tissue, using a microscope drawing tube that allowed visualization of a computerized measuring device.

\section{Results}

Results were obtained from 81 TTX-treated kittens. Their TTXinjected left eye will be referred to as the "deprived eye," and the LGN layers to which it projects as the "deprived layers." Most electrode penetrations were made in the left LGN to allow characterization of cells in normal layer $\mathrm{A}$, before deprived layer Al was encountered. The perigeniculate nucleus was not studied, nor were the C layers of the LGN, except for the first cell recorded below layer A1. Most cells recorded had receptive fields within $5^{\circ}$ of the horizontal and $25^{\circ}$ of the vertical visual midlines. This region was chosen so that electrode tracks would be approximately perpendicular to the LGN layer borders. This assisted us in defining the severely shrunken deprived LGN layers. The periphery out to and including the monocular segment was sometimes sampled, as were all but the most superior and inferior regions of the visual field. There was no obvious difference among the basic results found at any place in the visual field.

In all of the TTX-treated animals from which we recorded,

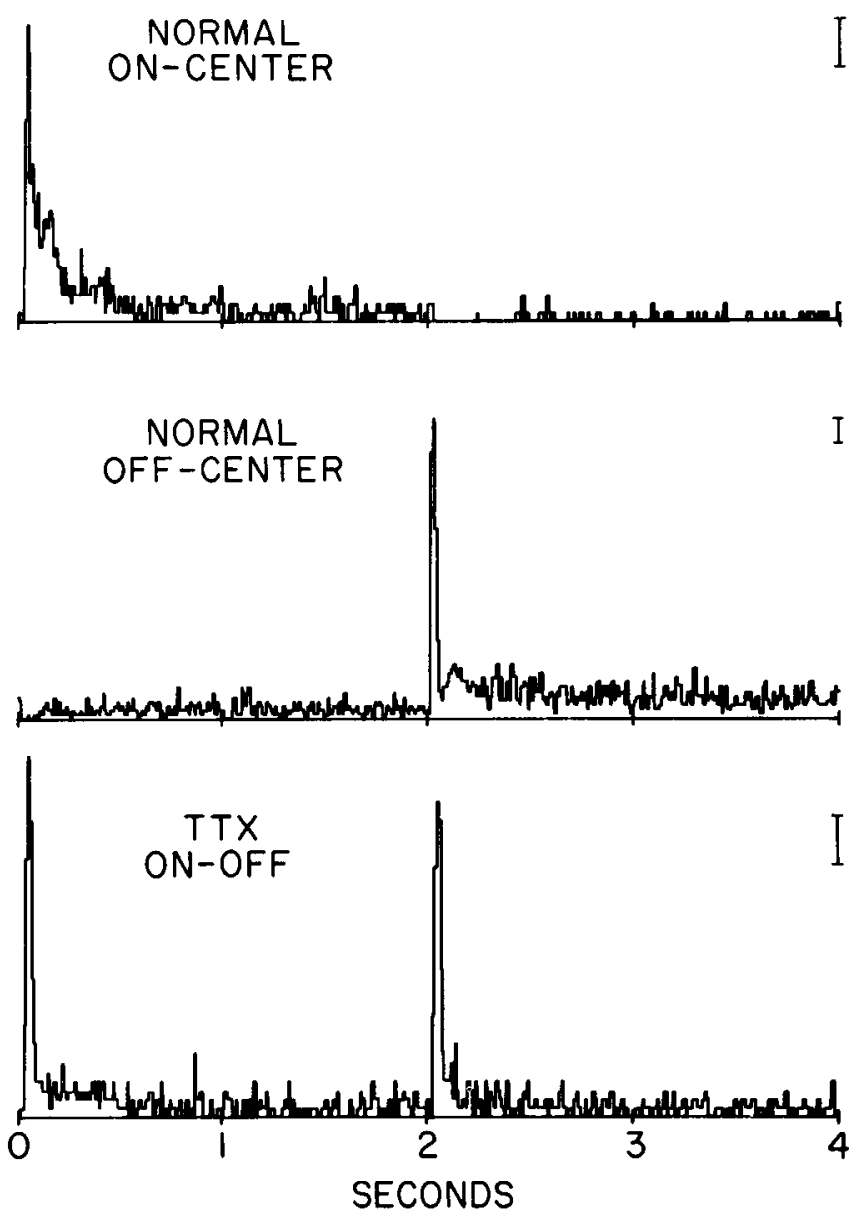

$\stackrel{\longrightarrow}{\leftarrow \text { LIGHT ON } \longrightarrow}$

Figure 2. Typical PSTH displays of the responses of cells in normal and TTX-deprived LGN layers to spots of light presented in the center of their receptive field. Spots were presented for $2 \mathrm{sec}$ out of every 4 $\mathrm{sec}$, as indicated by the bar at the bottom of the figure. The upper PSTH shows the response at light onset $\left(0.4^{\circ}\right.$ spot $)$ of a normal ON-center cell, the middle PSTH the response at light offset $\left(0.7^{\circ}\right.$ spot $)$ of a normal OFF-center cell. The lower PSTH shows the responses of an ON-OFF cell to an $0.8^{\circ}$ spot, which should be compared in size and latency with the responses of the normal cells. The vertical bars at right indicate 25 spikes/sec.

cells in the nondeprived layers were qualitatively normal. Both ON-center and OFF-center cells were encountered, and many were further characterized as X-or Y-type. These normal layers of the TTX-injected animals demonstrate that the effects of action-potential blockade found in the deprived layers were specific and were not systemic ones.

\section{ON-OFF cells}

A typical animal received TTX injections that produced actionpotential blockade from within $2 \mathrm{~d}$ of birth to age $35 \mathrm{~d}$ or later. It was then set up for LGN recording soon after the pupillary response returned. In these animals, most of the cells recorded in the deprived layers had responses similar to that illustrated in the bottom PSTH of Figure 2. The top two PSTHs of the figure show the responses of normal ON-center and OFF-center LGN cells to a spot of light presented in the center of the cells' receptive fields. These responses are characteristic of all normal A-layer cells, in that such cells only give an excitatory response either at light onset or offset (i.e., they are either ON- or OFFcenter). This is because LGN cells normally receive excitatory input only from ganglion cells of the same center sign (Cleland 

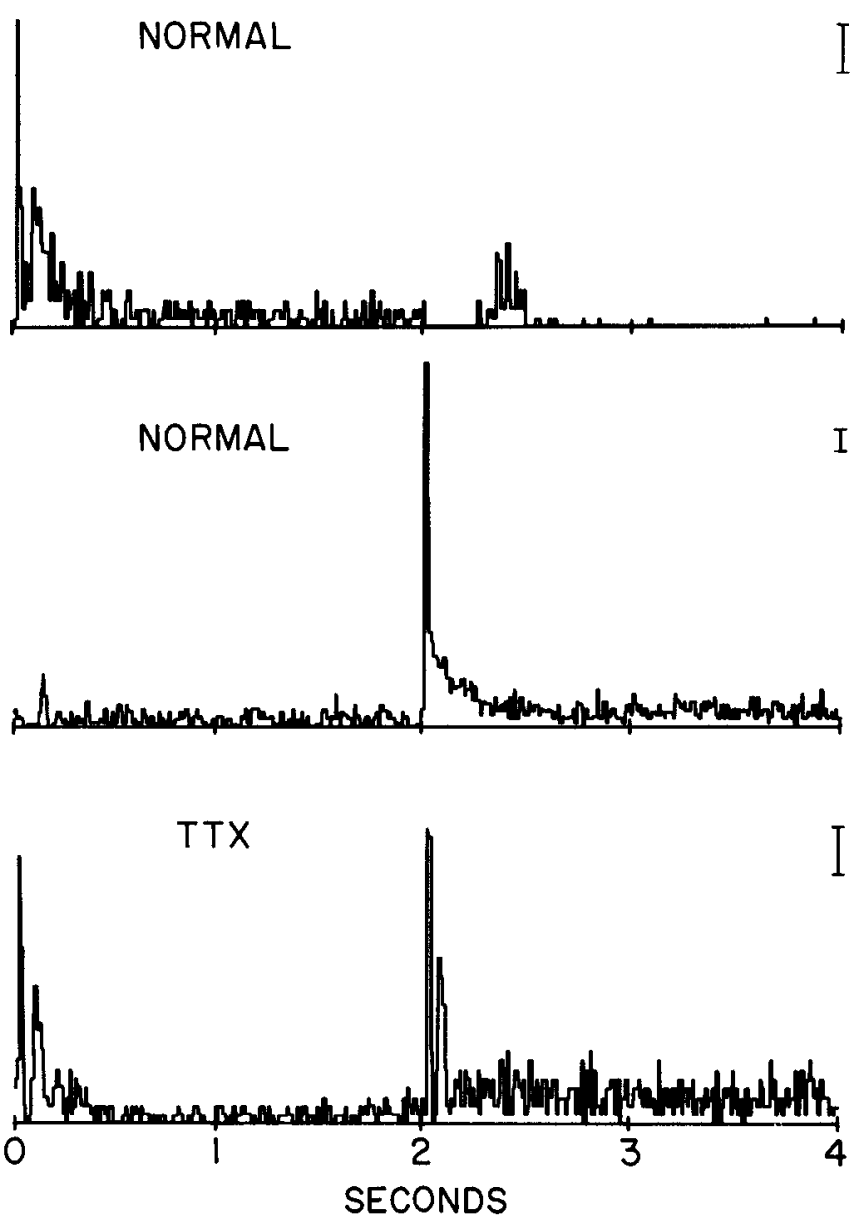

Figure 3. PSTH displays of responses of LGN cells to spots of light presented in the center of their receptive field, shown to distinguish between postinhibitory rebound and excitatory responses. The upper PSTH shows a normal ON-center cell with a pronounced postinhibitory rebound of firing in response to a $2^{\circ}$ spot, about $250 \mathrm{msec}$ after light offset. Compare this with the short-latency OFF response to a $1.3^{\circ}$ spot, of the normal OFF-center cell shown in the middle PSTH. (A small postinhibitory rebound after light onset can also be seen in this PSTH.) Note that the latency of firing at both light onset and offset for the ONOFF cell recorded in a TTX-deprived layer (lower PSTH, $1.5^{\circ}$ spot) is a short, excitatory latency, compared with the longer latency postinhibitory rebound. Conventions as in Figure 2.

et al., 1971). The cell illustrated in the bottom PSTH, driven by ganglion cells of a TTX-trcated eye, gave a response to both the onset and the offset of a centered spot of light. Such cells will be referred to as "ON-OFF." Both the ON and the OFF responses of ON-OFF cells had similar latencies to visual stimulation. These latencies were also similar to the excitatory latencies of normal ON- and OFF-center LGN cells in the same animal; they were typically $25-60 \mathrm{msec}$, depending on the size and intensity of the stimulus spot.

\section{Control experiments}

\section{Ganglion cell responses}

One possible explanation for ON-OFF units in the LGN of TTX-treated kittens is that they reflect the fact that retinal ganglion cells of the TTX-injected eye have become ON-OFF. To test this possibility, over 100 deprived-eye ganglion cells were recorded, either intraocularly or from their axons in and below the LGN, in animals in which ON-OFF cells were recorded in the LGN. In no case were ganglion cells other than $\mathrm{ON}$ - or OFFcenter type encountered (except for the few W-cells recorded). In two typical animals with ON-OFF cells in their LGN, 27 randomly encountered ganglion cells in the deprived eye were characterized using a battery of tests. These tests included PSTHs in response to the same type of stimuli used to define ON-OFF cells in the LGN. All of these ganglion cells were found to be ON- or OFF-center type, and almost all could also be readily characterized as X- or Y-type. Thus, the ON-OFF cells found in the LGN were the result of inappropriate synaptic connectivity in the LGN and not of retinal abnormalities induced in the injected eyes.

\section{Excitation vs inhibition}

We are defining ON-OFF cells as those that give an excitatory response, at both light onset and offset, to stimulation in their receptive field center. Thus, it is important to differentiate between excitatory responses and postinhibitory rebound responses that might be confused with excitation. This was often difficult to do when listening to the audio monitor, especially when moving largets were the stimulus used to study the receptive field. For this reason, all of the cells we classified were characterized by constructing PSTHs in response to flashing spots.

The difference between excitatory responses and inhibitory rebound is illustrated in Figure 3. In the top PSTH the response of a normal ON-center LGN cell to a large, centered, spot stimulus is shown. At light offset there was a period of inhibition, followed by a postinhibitory rebound of firing. The latency of such postinhibitory bursts typically ranged from 100 to 300 $\mathrm{msec}$, depending on stimulus parameters. This is significantly longer than a normal excitatory OFF-response latency (40-80 msec), such as the one shown in the center panel of Figure 3. Postinhibitory rebound was also often seen in OFF-center cells after a period of inhibition at light onset. In both ON- and OFFcenter cells, the latency of the rebound burst of firing was always significantly greater than the latency of the excitatory response. The lower PSTH of the figure shows the short latency of both responses of an ON-OFF cell, relative to the rebound firing shown in the top PSTHs.

\section{Surround responses}

Extensive attempts were made to demonstrate that the ONOFF cell responses were not artifactually elicited center and surround responses occurring simultaneously. We attempted to generate $\mathrm{ON}-\mathrm{OFF}$ type responses in normal $\mathrm{ON}$ - or OFF-center LGN cells by using very large and very small spots of various intensities. In a few cases, for Y-type LGN cells only, a clear surround response was elicited when a spot of light about $0.5^{\circ}$ $1^{\circ}$ in diameter was decentered by about $2^{\circ}$. In this situation, the center response was still present and was significantly larger than the surround response. More important, the surround response had a latency that was typically twice that of the center response. Decentering the stimulus never generated an ON-OFF response in which the response sizes and latencies were equal at stimulus onset and offset (as in the bottom PSTH of Fig. 3). Of the over 150 ON-OFF cells we recorded, only 3 units had responses with the latency at one phase significantly longer than that at the other.

The fact that decentering a spot stimulus could not artifactually generate an $\mathrm{ON}-\mathrm{OFF}$ response is significant because many of the ON-OFF cells had relatively ellipsoidal, elongated receptive fields. When these receptive fields were carefully explored with small stimuli, they often had "hot spots." That is, there were subregions within the receptive field that gave especially strong $\mathrm{ON}$ or OFF responses. Often, more than two such regions could be distinguished. The upper PSTH in Figure 4 shows the equal responses of such an ON-OFF cell to a cen- 

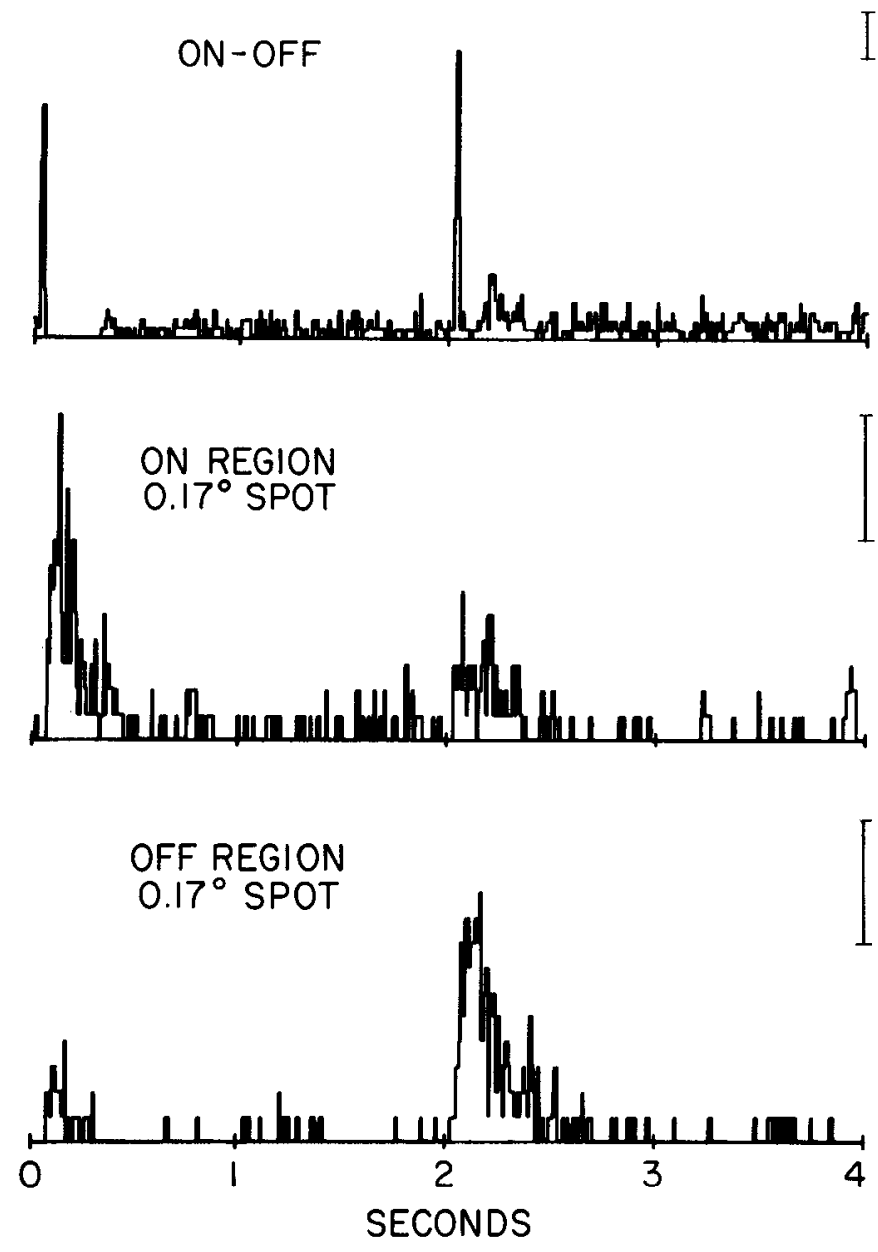

Figure 4. PSTH displays of an ON-OFF LGN cell showing responses of receptive field "hot spots." The upper PSTH shows the ON and OFF responses to a $1.5^{\circ}$ spot of light centered in the receptive field. The lower traces shows the responses of $\mathrm{ON}$ and $\mathrm{OFF}$ subregions of the receptive field to smaller, $0.17^{\circ}$, spots centered in those regions. Conventions as in previous figures.

tered $1^{\circ}$ spot. When the stimulus spot was reduced to $0.17^{\circ}$ in diameter, two regions about $0.66^{\circ}$ apart could be localized. In one, the ON response predominated, and in the other, the OFF response predominated, as shown in the lower two PSTHs, respectively. In all three PSTHs, the $O N$ and OFF response latency is about $40 \mathrm{msec}$. It seems reasonable to interpret such hot spots as being the receptive field centers of the excitatory ganglion cell inputs to the ON-OFF LGN cell being recorded. If so, they are ganglion cells whose centers do not overlap significantly. This would account for the receptive field elongation, as well as its subregions.

\section{Sham injection and monocular suture kittens}

A kitten had one eye injected for $43 \mathrm{~d}$ from birth with citrate buffer vehicle solution, not containing TTX. Three days after the last injection, we carefully studied 18 cells in the left LGN layer A1 of this sham-injected animal. All of these cells had normal receptive field properties. When examined later by light microscopy, the layer thicknesses and cell sizes in both LGN of this animal were normal. In another control experiment, a kitten's left eyelids were sutured from postnatal day 7 to day 80 . Then, the animal was set up for recording from its LGN, and its sutured eye opened. Although the cells of the deprived ge-
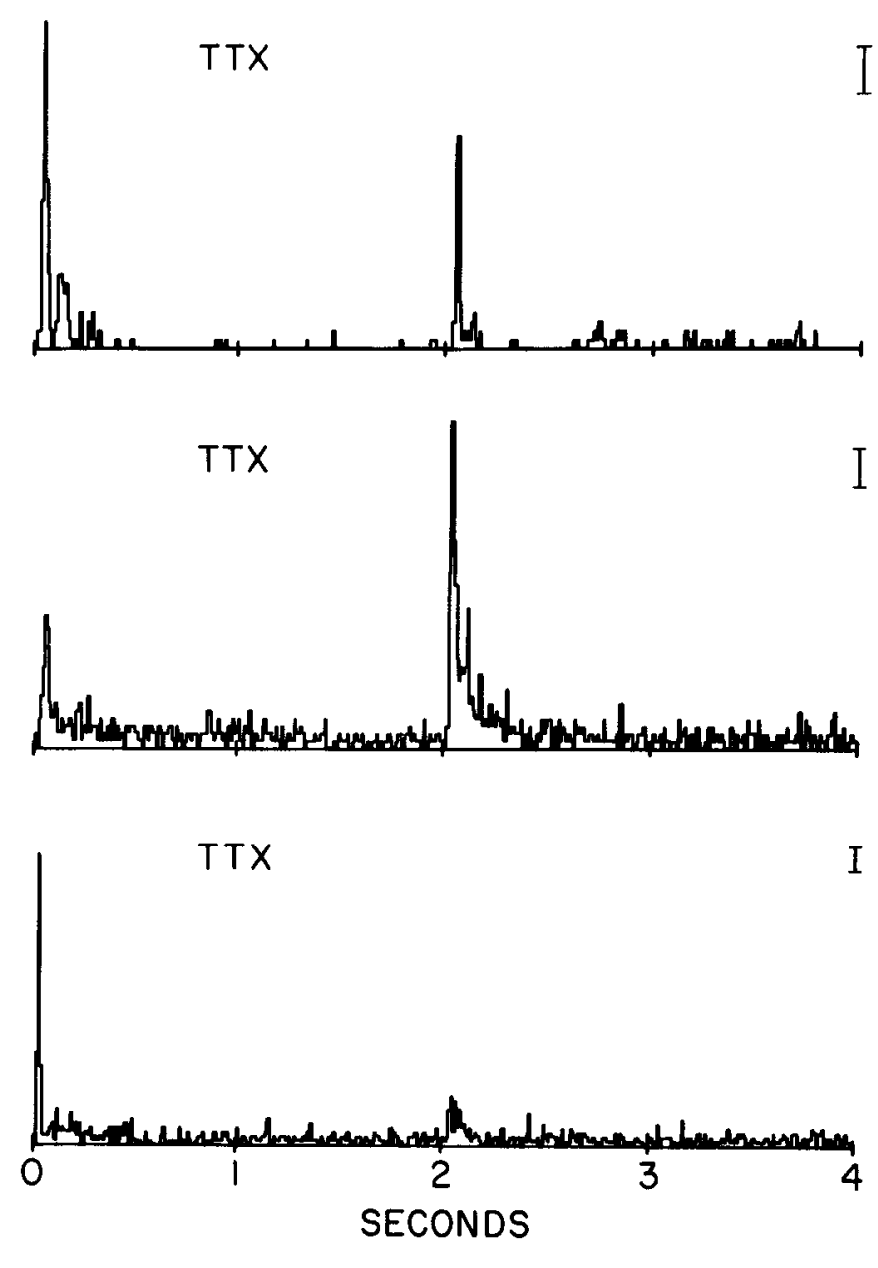

Figure 5. PSTH displays of different ON-OFF LGN cells illustrating unequal ON and OFF responses. Stimulus spot sizes: top, $1^{\circ}$; middle, $0.5^{\circ} ;$ bottom, $0.7^{\circ}$. Conventions as in previous figures.

niculate layers displayed the characteristics of monocular deprivation, such as spatially and temporarily indistinct responses, no ON-OFF type receptive fields were found among the 25 lefteye LGN cells that were intensively studied. This is consistent with the fact that ON-OFF cells in the LGN have never previously been reported as a result of any other type of visual deprivation. Thus, we conclude that ON-OFF cells in the LGN are a specific result of action-potential blockade.

\section{Response properties of $\mathrm{ON}-\mathrm{OFF}$ cells}

Inequality of $O N$ and $O F F$ responses

While the ON-OFF cells shown in Figures 2-4 had relatively equal $\mathrm{ON}$ and $\mathrm{OFF}$ responses, this was not always the case. As illustrated in Figure 5, some cells had a stronger response at one phase than the other, even when stimuli were optimized for the best response at both phases. The size of the weaker response often waxed and waned as a function of the maintained firing rate of the cell, being largest when the spontaneous rate was greatest. There was no tendency for cells to be stronger at one phase than the other. In a sample of 90 well-characterized ONOFF cells from several different animals, there were 31 units in which the $O N$ response was clearly stronger, 27 in which the ON and OFF responses were approximately equal, and 32 in which the OFF response was clearly stronger. The bottom PSTH (Fig. 5) shows a cell that was characterized as a "weakly ON- 
A

Figure 6. PSTH displays of responses to a $1.4^{\circ}$ spot of light presented in the center of the receptive field of an LGN $\mathrm{ON}-\mathrm{OFF}$ cell $(C)$ and, similarly, to two of its retinal ganglion cell inputs, one ON-center $(A)$ and one OFF-center $(D)$ Conventions are as in previous figures. The relative positions of the centers of the receptive fields of the three cells are shown in the small schematic (middle of right column): The circular symbol $(\oplus)$ represents the center of the receptive field of the LGN cell; $F$, the receptive field center of the OFF-center ganglion cell; and $N$, the receptive field center of the ON-center ganglion cell. $B$, Cross-correlogram of the spontaneous firing of the ON-center ganglion cell with the spontaneous firing of the LGN cell. Note the sharpness of the peak, indicative of a monosynaptic input. $E$, Similar cross-correlogram between the OFF-center ganglion cell and the LGN cell.

C
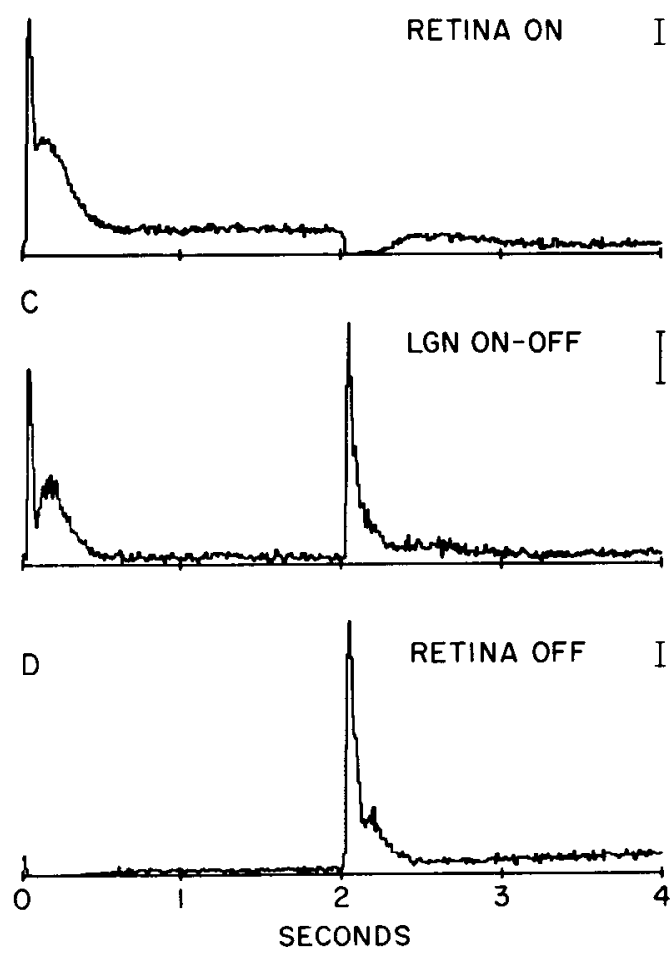

B

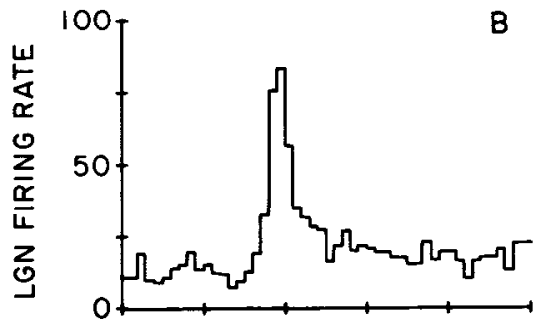

$F \oplus N$
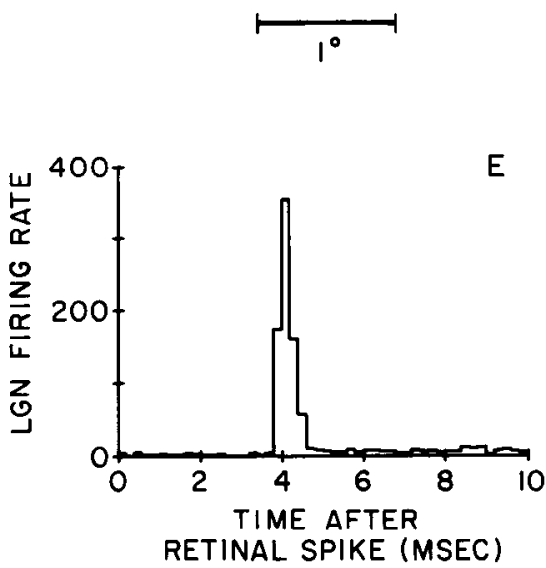

OFF" unit (see below); such cells usually were found only in animals that had long postinjection recovery periods prior to recording.

\section{Receptive field elongation}

Over half of all units in the deprived layers had noticeably elongated receptive fields. A somewhat surprising finding was that, in almost all cases, the long axis was approximately horizontal, independent of visual field position. No extensive effort was made to quantify this parameter, which was normally determined by the cell's response to moving wands and flashing spots. Thus, these fields could have had orientations up to $30^{\circ}$ from horizontal, which would not have been easily noted. However, a long axis $45^{\circ}$ or more from horizontal would readily have been characterized as such.

\section{Other receptive field properties}

Most units in the deprived layers did not respond as crisply or as strongly as those in the normal layers, and were somewhat spatially diffuse. Their receptive fields were often large, sometimes amorphous, and had borders that were difficult to define. These characteristics are similar to those of cells recorded in the LGN of very young normal kittens. About $10 \%$ of the cells encountered in the deprived layers could not be driven visually, although their presence was evident from their spontaneous firing. No correlation was found between the presence of these unresponsive cells and any of the parameters of TTX treatment, such as duration of action-potential blockade or amount of postTTX recovery time.

\section{Effects in MIN, monocular segment, and layer $A$}

The MIN of the right LGN was recorded in a kitten that had received TTX injections for $74 \mathrm{~d}$ from birth and was set up for recording $42 \mathrm{~d}$ later. Several $\mathrm{ON}-\mathrm{OFF}$ units were observed and verified by PSTHs; however, no effort was made to quantify the degree of abnormality.
In two animals that had action-potential blockade maintained for more than $75 \mathrm{~d}$ from birth, an increasingly lateral progression of electrode penetrations was made in the right LGN until cells in the monocular segment of deprived layer $A$ were recorded. Receptive field positions were more than $55^{\circ}$ lateral to the midline. In both animals, many ON-OFF units were found in the deprived monocular segment. Although they had large receptive fields typical of units in the far periphery, they were otherwise similar to ON-OFF cells recorded in the binocular portions of the LGN.

We determined that $\mathrm{ON}-\mathrm{OFF}$ cells were not unique to layer A1 of the geniculate by recording from deprived layer $A$ of the right LGN in 10 TTX-treated animals, most of which had received 7-10 weeks of action-potential blockade. ${ }^{2}$ In all of these animals we found ON-OFF cells that showed the same properties, such as elongation and hot spots, as those found in deprived layer Al of the left LGN.

\section{Simultaneous recording from retina and $L G N$}

We interpret the PSTHs of ON-OFF units as implying that such cells receive simultaneous, excitatory input from both $\mathrm{ON}$ - and OFF-center retinal ganglion cells. This is based on both the latency and form of the responses to flashing spots of light, as well as our surround-response control experiments. In normal cats such excitatory inputs are monosynaptic (Cleland et al., 1971; Mastronarde, 1983a). ON-OFF cells in the deprived LGN layers were directly tested, to determine whether both the $O N$ and OFF inputs were monosynaptic, by simultaneously record-

${ }^{2}$ Cells in the perigeniculate nucleus, immediately above layer A, normally have ON-OFF-type receptive fields that are somewhat similar to those of the LGN ON-OFF cells brought about by action-potential blockade. We differentiated between the perigeniculate nucleus and deprived layer $A$ in two ways. First, if a clear ON- or OFF-center cell was recorded, then all cells encountered deeper in the penetration could confidently be assigned to the LGN proper. Second, once in layer A, a characteristic background "swish" could be heard on the audio monitor in response to a light flashed into the eye. 
Table 1. Types of inputs found to nine ON-OFF LGN cells

\begin{tabular}{llc} 
Cell & $\begin{array}{l}\text { Ganglion cell } \\
\text { input type }\end{array}$ & $\begin{array}{c}\text { Contri- } \\
\text { bution } \\
(\%)\end{array}$ \\
\hline $25 X-3$ & ON-X & 3 \\
$38 X-1$ & OFF-Y & 35 \\
& ON-Y & 10 \\
$38 X-3$ & OFF-Y & 40 \\
$29 X-1^{c}$ & ON-Y & 7 \\
$29 X-3$ & OFF-Y & 10 \\
& OFF-Y & 10 \\
$29 X-4$ & OFF-Y & 40 \\
$29 X-5 c$ & OFF-Y & 2 \\
$34 X-9$ & OFF-Y & 2 \\
$34 X-13$ & OFF-Y & 10 \\
& OFF-Y & 8 \\
& OFF-Y & 15 \\
& OFF-Y & 40
\end{tabular}

${ }^{a}$ Contribution is the fraction of the LGN cell spikes occurring in the crosscorrelogram, and thus directly caused by the ganglion cell input.

"Same ganglion cell as in $38 \mathrm{X}-1$.

c LGN cell binocular as well as $\mathrm{ON}-\mathrm{OFF}$.

${ }^{d}$ Same ganglion cell as in $29 \mathrm{X}-4$.

ing from an ON-OFF cell and from the retinal ganglion cell or cells that provided excitatory input to it (Cleland et al., 1971).

At least one retinal input was successfully found for each of nine ON-OFF LGN cells recorded in a total of four animals, as shown in Table 1. All of the inputs were excitatory and monosynaptic, as determined by cross-correlograms (Cleland et al., 1981; Mastronarde, 1983a). There were two ON-OFF cells for which both ON- and OFF-center inputs were successfully located. For other cells, only one input or one type of input was found, but we assume that a more successful search would have found other inputs. ${ }^{3}$ In two cases we were able to advance the geniculate electrode after a search was made, record a second, nearby ON-OFF cell, and find that the two geniculate cells had a ganglion cell input in common. In two cases the LGN cell was binocular as well as ON-OFF.

Figure $6 C$ shows the PSTH of LGN ON-OFF cell $38 \mathrm{X}-1$, for which both $\mathrm{ON}$ - and $\mathrm{OFF}$-center ganglion cell inputs were found. Figures $6, A$ and $D$, shows the PSTHs of the two inputs. Figure $6, B$ and $E$, shows the cross-correlograms of the spontaneous firing of each input and the firing of the ON-OFF ccll; in both, the sharpness of the correlogram peak at a latency of $3.6 \mathrm{msec}$ indicates the input was monosynaptic (Cleland et al., 1971; Mastronarde, 1983a).

Since both ganglion cells found to be inputs to $38 \mathrm{X}-1$ were $Y$-typc and the animal was over a year old when tested, it was surprising that the latency from ganglion cell firing to LGN cell firing was $3.6 \mathrm{msec}$. In normal adult cats, the same latency for a Y-type input would be $2.0-3.0 \mathrm{msec}$. Thus, to be sure that the $3.6 \mathrm{msec}$ latency was not due to a polysynaptic input, we carried out the following control. After recording the ON-OFF

\footnotetext{
${ }^{3}$ These "dual recording" experiments were much more difficult to carry out in TTX-treated kittens than in normal animals. In a dual recording experiment, the initial step is to record and carefully plot the position of the LGN cell, which then serves as the reference point for the subsequent search for its retinal inputs. The typical ON -OFF LGN cell had a rather large receptive field, thus making the reference point somewhat ambiguous. The intraocular search of the retina typically requires many penetrations of a confined region of the retina by the recording electrode. Retinas of TTX-treated eyes were especially sensitive to electrode penetration; no cells could be isolated in any local region after a few electrode touches in that region. Thus, many searches had to be abandoned prematurely.
}

Table 2. Cells in deprived LGN layers tested with electrical stimulation for $\mathbf{X}$ and $\mathrm{Y}$ inputs

\begin{tabular}{|c|c|c|c|}
\hline LGN cell type & $\begin{array}{l}X \text { and } Y \\
\text { latency }\end{array}$ & $\begin{array}{l}\mathrm{X} \\
\text { latency }\end{array}$ & $\begin{array}{l}\text { Y } \\
\text { latency }\end{array}$ \\
\hline Monocular ON-OFF & 5 & 0 & 2 \\
\hline Monocular ON or OFF & 1 & 2 & 1 \\
\hline Binocular & 4 & 0 & 1 \\
\hline
\end{tabular}

cell and its inputs, we replace the LGN recording electrode with an electrical stimulating electrode positioned at the identical place in the LGN. We then recorded two OFF-center and one $\mathrm{ON}$-center $\mathrm{Y}$-type ganglion cells in the same general region of the retina as the previously recorded inputs. Their latency was $3.0 \mathrm{msec}$ to retrograde stimulation from the LGN. The $0.6 \mathrm{msec}$ difference between this latency and the $3.6 \mathrm{msec}$ latency of the postsynaptic spikes of the ON-OFF cell as determined by the cross-correlograms is what would be expected for a monosynaptic delay time. All of the inputs shown in Table 1 have longer latencies than similar type inputs in normal cats, suggesting slower axonal conduction rates in the TTX-treated cats, perhaps due to axon shrinkage.

\section{$X$-cell and $Y$-cell input mixing after action-potential blockade}

$\mathrm{X}$ - and $\mathrm{Y}$-type retinal ganglion cells project to separate $\mathrm{X}$ - and Y-cells in the normal LGN, although about $10-15 \%$ of LGN cells receive input from both types (Cleland et al., 1971; Mooney et al., 1979). We were interested in determining whether this segregation of $\mathrm{X}$ - and $\mathrm{Y}$-type inputs broke down as a result of action-potential blockade, as did the segregation of ON- and OFF-center inputs. This could not be done routinely by simply noting receptive field properties. The combination of abnormalities and the property of being ON-OFF made it difficult, if not impossible, to determine whether a deprived LGN cell was X-type, Y-type, or mixed, based on its responses to the battery of standard visual tests. To circumvent this problem, a few animals were prepared with an intraocular stimulating electrode touching the optic disk. It is possible to see that an LGN cell with both $\mathrm{X}$ and $\mathrm{Y}$ inputs sometimes responds to electrical stimulation at the optic disk with an $\mathrm{X}$ latency and sometimes with a $Y$ latency, indicative of the fact that the unit has both excitatory $X$ - and Y-type ganglion cell inputs. ${ }^{4}$ LGN cells were tested in this way in three kittens that had received 44,45 , and $79 \mathrm{~d}$ of action-potential blockade from birth. The 44 and $45 \mathrm{~d}$ animals were tested $9 \mathrm{~d}$ after TTX treatment; the $79 \mathrm{~d}$ animal, $174 \mathrm{~d}$ after TTX. Table 2 shows that 10 out of 16 cells tested had both $X$ and $Y$ response latencics, suggesting that about $63 \%$ of LGN cells in the deprived layers had mixed $X$ - and $Y$-type inputs. This percentage is significantly greater than the 10-15\% found in normal animals.

The responses of an ON-OFF LGN unit with mixed $X$ and $Y$ inputs are shown in Figure 7. The upper PSTH shows the response to a visual stimulus; the lower histogram shows the responses to electrical stimulation plotted against the latency of each spike. The electrically driven spikes fell into two latency groups, which peaked at about 2.5 and $4.2 \mathrm{msec}$. These response peaks were not due to a burst of spikes to each stimulus; typically a stimulus only elicited a single spike. Some $48 \%$ of the spikes fall into the early peak and $37 \%$ in the later peak. Most of the

\footnotetext{
${ }^{4}$ In normal cats the conduction times from the retina to the LGN for X-and $\mathrm{Y}$-type ganglion cell axons fall into two well-separated groups, with $\mathrm{X}$-cells having the longer conduction time (Mooney et al., 1979). Thus, when recording from cells in the LGN and electrically stimulating at the optic disk, a relatively nonoverlapping bimodal latency distribution is found. For a 59-d-old normal kitten, the firing latencies of a collection of many LGN cells were about $2 \mathrm{msec}$ for Y-cells and $4 \mathrm{msec}$ for $\mathrm{X}$-cells, in response to disk stimulation.
} 


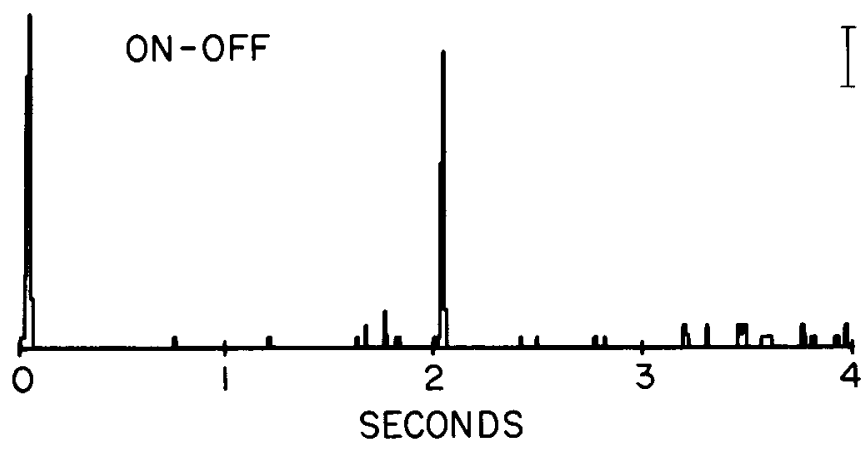

$\Gamma$

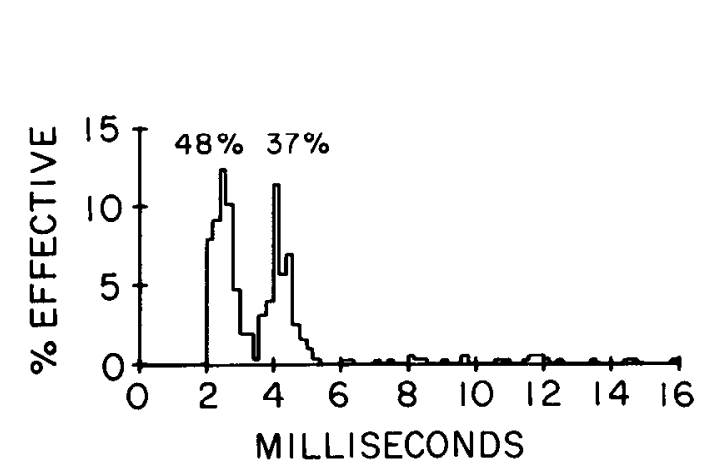

Figure 7. Responses of an ON-OFF LGN cell that was shown to receive excitatory X-and Y-type ganglion cell input. Upper panel, PSTH display of the LGN cell's response to a $2.7^{\circ}$ spot of light centered in the receptive field; conventions as in previous figures. Lower panel, PSTH responses of this same cell to electrical stimulation at the optic disk. The ordinate shows the percentage of stimuli that were effective in causing a response in each of the $0.2 \mathrm{msec}$ bins plotted on the abscissa. The abscissa shows time (msec) after the stimulus. The response has two peaks at about 2.5 and 4.2 msec. Forty-eight percent of the spikes in response to the electrical stimulus fell in the early peak and $37 \%$ in the later one.

$\mathrm{X}-\mathrm{Y}$ cells had about equal numbers of $\mathrm{X}$ - and $\mathrm{Y}$-driven spikes, with neither type occurring much over $50 \%$ of the time.

\section{Binocular cells}

Units excited by one eye and inhibited by the other have been reported to be common in normal cats (Sanderson et al., 1971), and were also seen in the TTX-treated animals. However, cells that are excited by both eyes are very rarely found in the LGN of normal kittens and cats (Sanderson et al., 1971); extensive recording in normal animals usually does not yield a single binocular unit. In contrast, animals that have undergone actionpotential blockade that produces ON-OFF units also have many binocularly excited cells in both the right and left LGN. The responses of such a cell are illustrated in Figure 8. The upper PSTH shows the OFF-center response of the cell when it was stimulated through the animal's normal, right eye. When stimulated through the animal's deprived eye, this same cell gave an ON-OFF response as shown in the lower PSTH. In animals that had received more than $35 \mathrm{~d}$ of action-potential blockade from birth and that were then studied before significant postTTX recovery had occurred, 22 binocular cells were found at 51 border crossings (either $\mathrm{A} / \mathrm{Al}$ or $\mathrm{Al} / \mathrm{C}$ ). This encounter rate of $43 \%$ suggests that binocular units are a common result of action-potential blockade.

Binocular cells generally had responses of equal strength, or ones in which the response through the normal eye was stronger. Only 2 of 22 well-characterized binocular units had a significantly stronger response elicited by the TTX-injected eye. Units

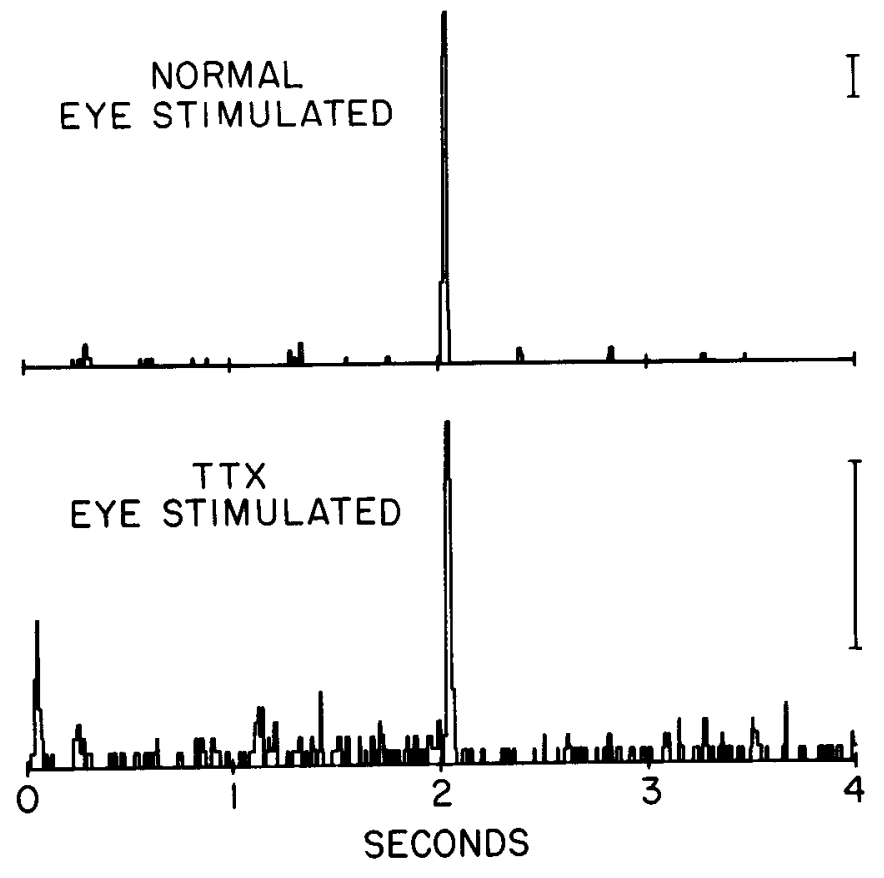

Figure 8. PSTH displays of responses of a binocular LGN cell to $1.2^{\circ}$ spots of light centered in the receptive field, presented separately to each eye. The upper PSTH shows the OFF response of this cell elicited through the uninjected eye; the lower PSTH, the ON-OFF response elicited through the TTX-treated eye. Conventions as in previous figures.

were found in all possible permutations; the receptive field characterized via the normal eye could be ON- or OFF-center, coupled with a left eye receptive field that was ON- or OFF-center or ON-OFF. In two binocular units the right eye receptive field was $\mathrm{ON}-\mathrm{OFF}$. In both units the right eye responses were sluggish and the fields hard to localize, thus making further interpretation of these cells difficult. For three other binocular units the response through the right eye was directionally selective; each unit responded best to a bar moved in a particular direction and little or not at all to the bar moved in the exactly opposite direction. The directional preference was independent of whether the bar was lighter or darker than the gray background against which it was presented. These LGN cells may have received their right eye input from a directionally selective, W-type ganglion cell or from an efferent axon from the cortex.

Binocular cells were usually found in the region of layer transition, where recording along an electrode track was shifting from one eye to the other. The retinotopic positions of their receptive fields in each eye were usually similar. A careful determination of the visual midline was not made in most experiments, so the exact degree of correspondence between the receptive fields cannot be stated. However, the results were consistent with the fact that in all animals recorded, the deprived LGN layers had relatively undistorted retinotopic maps that were in general register with those of the adjacent normal layers. In some cases the cells of adjacent LGN layers seemed to be intermixed, as shown by recording simultaneous, multiunit activity from both eyes. However, many electrode tracks encountered a zone between layers that was about $100 \mu \mathrm{m}$ wide and in which no units and only faint background activity could be recorded.

\section{Recovery from action-potential blockade}

Experiments were carried out to determine whether recovery of normal receptive field responses could occur in the deprived 


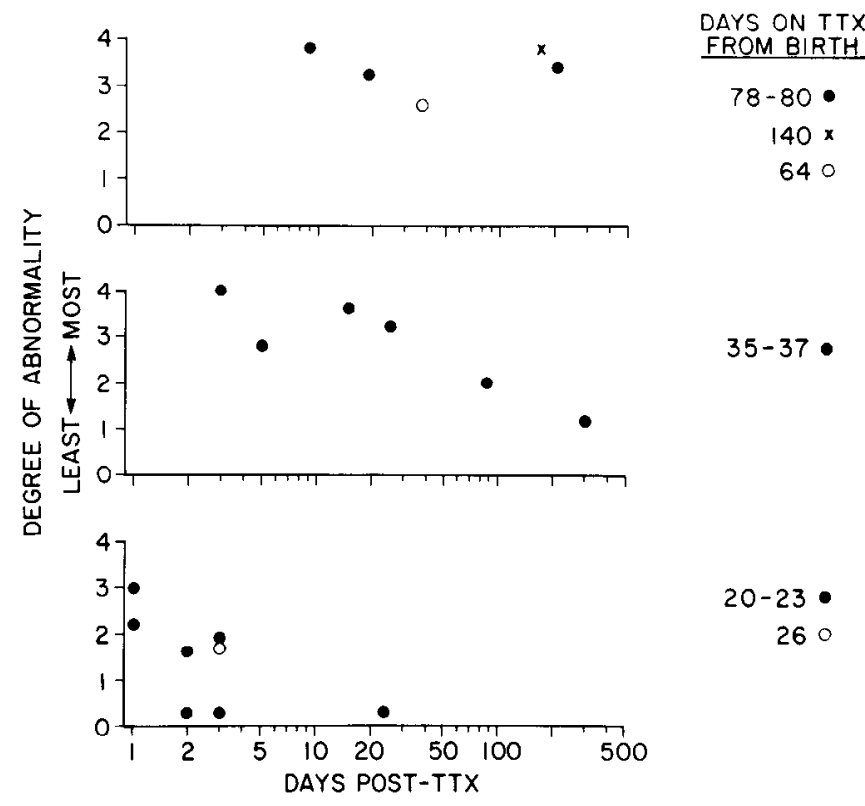

Figure 9. Degree of $\mathrm{LGN}$ recovery in layer $\mathrm{Al}$ as a function of time following TTX treatment. The ordinate of each graph is the abnormality score (see text). The abscissas represent the number of days that were allowed after action-potential blockade had ended before recording from the animal. Each point represents a single animal treated from birth for the length of time indicated by the symbols defined at the right of the figure. For animals shown in the upper two graphs, ganglion cell activity was arbitrarily taken to begin $2 \mathrm{~d}$ after the last TTX injection. This is an underestimatc of $12-24 \mathrm{hr}$, but is clcarly inconscqucntial in assessing the results. For animals represented in the lowest graph, where recovery at brief times after TTX treatment is apparently fast, the return of activity was judged by determining when a pupillary reflex could first be elicited in the TTX-treated eye.

LGN layers. Sets of animals were injected with TTX for approximately 3,5 , or 11 weeks from birth. Kittens in each set were allowed different lengths of time after their last injection before we recorded from the left LGN.

To compare the data from the 19 animals used, a standardized method of quantifying the degree of abnormality in their deprived LGN layers was developed. First, each cell was determined to be ON-center, OFF-center, ON-OFF, or binocular. Next, the cell was characterized in terms of how well it could be localized, how elongated its receptive field was, and how responsive it was (see Table 3 ). Then, the cell was given a single, overall numerical score from $0-4$, based on these parameters (Table 4). Finally, an overall score for the degree of abnormality in each animal was calculated by adding the scores for all of the cells characterized in its deprived layer, and dividing by the number of such cells. Thus, each animal's degree of abnormality is indicated by a number between 0 and 4, with higher scores indicating a greater number of units with high abnormality. For all animals, only those cells for which PSTHs were collected were included in the score. This assured that $\mathrm{ON}-\mathrm{OFF}$ cells were properly identified. For units classified as binocular, PSTHs were run for each eye separately. Almost every animal had at least 10 PSTH-characterized units. ${ }^{5}$

The overall abnormality score was designed to differentiate cells in a clear way, yet to be as simple as possible. Thus, it

\footnotetext{
${ }^{5}$ Sample size was somewhat small because it was difficult to isolate units in the severely shrunken, deprived layers. Spikes were usually not large relative to the background noise. Often, 30-60 min was spent carefully moving the electrode over a range of 50-100 $\mathrm{mm}$ within the deprived layer in order to isolate a spike well enough to assure that it was the only one contributing to the subsequently built PSTH. In addition to the 19 animals shown in Figure 9, another 7 animals had scores consistent with the data presented in the figure but are not included because of the small number of cells in each for which PSTHs were obtained.
}

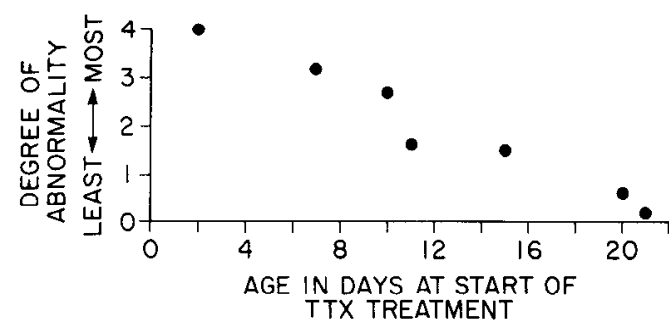

Figure 10. Degree of LGN abnormality in layer A1 as a function of age at which TTX treatment was started. The ordinate of the graph is the abnormality score, as defined in the text and used in Figure 9. The abscissa represents the postnatal age at which action-potential blockade was started. Each point represents a single animal. All animals had at least $32 \mathrm{~d}$ of blockade and were set up for recording before any substantive recovery could have occurred.

must be emphasized that a cell with an overall score of 4 is not meant to be thought of as $4 \times$ more abnormal than a cell with a score of 1 . Rather, the scale implies that cells with higher scores are simply more abnormal. Weakly ON-OFF cells are considered to be less abnormal than strong ON-OFF cells for the following reason. Weakly ON-OFF units were usually found only in animals in which there were many ON- or OFF-centertype cells in the deprived layers. Cells in these layers also had responses that were at the normal end of the scales in Table 2. That is, weakly ON-OFF cells were found in animals in which the deprived layers of the LGN were more normal overall.

Figure 9 indicates the degree of recovery in each of the three sets of animals studied. Each point represents one animal. The top panel of the figure shows that for animals receiving 11 or more weeks of action-potential blockade from birth, most of the cells encountered in the deprived LGN layer were ON-OFF and/or binocular, even $200 \mathrm{~d}$ after the last TTX injection. 'The middle panel of the figure illustrates that some recovery can occur after 5 weeks of action-potential blockade, but it is slow and incomplete. By 12 weeks post-TTX, the encounter rate of ON-OFF or binocular units was down to $50 \%$ of all units classified; by $300 \mathrm{~d}$ post-TTX, 5 of 18 units were ON-OFF or binocular. In these animals, encounter rates of binocular units suggested that these cells may not recover as fast or completely as do ON-OFF units.

The most significant degree of recovery was seen in animals that received TTX for only 3 weeks from birth. As shown in the lowest panel, these kittens could recover to the point where no ON-OFF or binocular cells were encountered, and even the other abnormalities were not significantly present. ${ }^{6}$ This recovery occurred very quickly after the return of ganglion cell activity. Even for the two animals that were recorded on the same day as the TTX blockade was ending, the abnormality score is not 4. That is, in both of these animals, some ON- and OFFcenter units were encountered in the deprived layer of the LGN. This raises the question of whether recovery was so fast that some ON-OFF units recovered to become ON- or OFF-center before we could record from them, or whether some units had never been ON-OFF.

A factor that bears on this question is that all ganglion cells did not regain their activity at the same time. This was determined in a 25-d-old kitten and an adult cat, each of which received one intraocular TTX injection, with single-unit re-

\footnotetext{
${ }^{6}$ In these kittens the cells encountered in normal layer A were immature and had parameter scores on the scales of Table 3 that were usually greater than 1 . Thus, such cells appeared "abnormal" due to their immaturity. In cach of these young animals, many cells in normal layer $A$ were recorded and scored, and an average score for layer $A$ cells (typically $0.2-0.5$ ) was calculated. To account for non-deprivation-induced, immature development, this score was subtracted from the average score of deprived layer Al cells in the calculation of the final abnormality score of the animal.
} 
Table 3. Characterization parameters for each cell recorded

Ease of localization
1, Normal
2, Almost normal
3, Diffuse but definable
4, Amorphous
5, Unlocalizable (position estimated from simultaneously recorded
$\quad$ background "swish")
Elongation
1, Symmetric
2, Moderate
3, Extreme, one dimension more than $3 \times$ the other
Responsiveness
1, Crisp response
2, Almost normal
3, Somewhat responsive
4, Barely responsive
5, Unresponsive

cording from the retina started before any release from actionpotential blockade had occurred. The pattern of recovery was similar in both animals. When a cortical VER to a flash of light could first readily be noticed, there were no ganglion cells that fired spontaneously. Furthermore, very few ganglion cells could be recorded, and those that were gave only a single action potential to a bright flash of light. Over the course of the next 24 $\mathrm{hr}$ more and more ganglion cells could be recorded. By the end of that time, many units with spontaneous activity were encountered. Encounter rates suggested that $\mathrm{ON}$-center ganglion cells may have recovered sooner than OFF-center ones. In summary, it was clear that not all ganglion cells regained their activity at the same time, even if they were neighbors. Thus, for the animals shown in the bottom panel of Figure 9, it is possible that when recording in the LGN very early in the period when action potentials were returning, some ON-OFF units might have appeared ON- or OFF-center because not all of their ganglion cell inputs had yet recovered from the action-potential blockade.

\section{Period of susceptibility to action-potential blockade}

In a group of seven animals, TTX injections were begun between 2 and $21 \mathrm{~d}$ of age. Action-potential blockade was then maintained for 32-56 d and the animals were all set up for recording within 3-7 d after the blockade had ended. The abnormality scores of these animals are plotted in Figure 10. It can be seen that the later within this 3 week postnatal period that actionpotential blockade was initiated, the lower the abnormality scores for the LGN. However, even in the animal with TTX injections started as late as day 15,4 of the 12 layer $\Lambda 1$ units scored were $\mathrm{ON}-\mathrm{OFF}$ cells. These results suggest that by about 3 weeks of age a normal developmental process leading to input segregation has occurred that cannot be reversed by subsequent actionpotential blockade.

\section{LGN cells in normal young kittens}

A possible explanation for the existence of ON-OFF units is that such cells were present in the LGN at birth, and that their normal development into $\mathrm{ON}$ - or OFF-center units was inhibited by the action-potential blockade of their retinal afferents. This hypothesis was tested by recording from the LGN of normal young kittens. A total of $58 \mathrm{LGN}$ cells were recorded in four kittens aged 6-17 d, and 45 units in seven kittens aged 22$29 \mathrm{~d}$. All 103 cells were classified with PSTHs and found to be
Table 4. Abnormality seale: overall score assigned to each cell encountered

\begin{tabular}{|c|c|}
\hline Score & Characteristics \\
\hline 4 & ON-OFF or binocular \\
\hline 3 & $\begin{array}{l}\text { Weakly ON-OFF. Initial peak of response at one phase more } \\
\text { than } 4 \times \text { greater than response at other phase }\end{array}$ \\
\hline 2 & $\begin{array}{l}\text { ON- or OFF-center and highly abnormal. Two out of three } \\
\text { parameters in Table } 1 \text { in the upper half of their scale, the other } \\
\text { abnormal }\end{array}$ \\
\hline 1 & ON- or OFF-center and moderately abnormal \\
\hline 0.5 & $\begin{array}{l}\text { ON- or OFF-center, and barely abnormal; two parameters in } \\
\text { Table } 1 \text { with scores of } 2 \text { or one parameter score of } 3\end{array}$ \\
\hline 0 & Normal \\
\hline
\end{tabular}

Scores of 3 and 4 are reserved for those properties strongly associated with actionpotential blockade, namely, ON-OFF receptive fields and binocular units. In the range $0.5-2$, cells are ON- or OFF-center, but still show parameters that mark them as abnormal. The subdivision of this abnormality into three categories "barely, moderate, highly," rather than just two, was donc because it allowed the normally immature cells of 3- to 4-week-old animals to be more directly compared with those of older animals (see text).

either ON-or OFF-center; $n o$ ON-OFF cells were encountered. The cells in the youngest animals were clearly immature relative to those in older animals; response latencies decreased and responsiveness increased as a function of animal age.

Although we did not record from animals younger than 6-dold, ON-OFF cells are found in kittens in which action-potential blockade is not started until 6-15 d of age, as was pointed out in relation to Figure 10. As a specific test of this point, TTX injections were started at $7 \mathrm{~d}$ of age in a littermate of the normal 6-d-old kitten reported here. Action-potential blockade was continued for $56 \mathrm{~d}$ and the kitten was recorded $3 \mathrm{~d}$ thereafter. It had an abnormality score of 3.2 , which represents nine ONOFF cells, one binocular cell, and three ON- or OFF-center cells.

\section{Anatomy of deprived LGN layers}

It was evident when recording that the deprived LGN layers were shrunken. In long-term TTX-treated animals, deprived layer Al could be recorded in a perpendicular electrode penetration for a distance of abut $250 \mu \mathrm{m}$. Laycr A just above it was usually recorded for a distance of about $800 \mu \mathrm{m}$. The reverse situation was found in the right LGN; deprived layer A was about $200-300 \mu \mathrm{m}$ thick, with normal layer Al being about 800 $\mu \mathrm{m}$ thick. In other work from this laboratory, we have found that in normal animals older than 8 weeks, both layers are typically recorded for a distance of about $500-600 \mu \mathrm{m}$.

These electrophysiological findings were confirmed by light microscopy of the LGN of many TTX-treated animals. [Electron-microscopic observations of the LGN of TTX-treated animals have been briefly reported (Kalil et al., 1983, 1985) and will be reported at length in another paper.] Figure 11 shows typical light-microscopic results. In deprived layer A1 (left LGN) and deprived layer A (right LGN), the layers and cell bodies were shrunken, and there may have been cell loss, especially in the lateral binocular portion of deprived layer A. In contrast, the nondeprived layers were much thicker, and appeared to have more cells than in an untreated animal. The monocular segment of deprived layer A was not as severely affected as the binocular portions of the layer.

\section{Retinal ganglion cell anatomy}

There was cell-body shrinkage of the retinal ganglion cells in IT'X-injected eyes. Alpha-type ganglion cells were chosen for quantitative study of this shrinkage because of their character- 

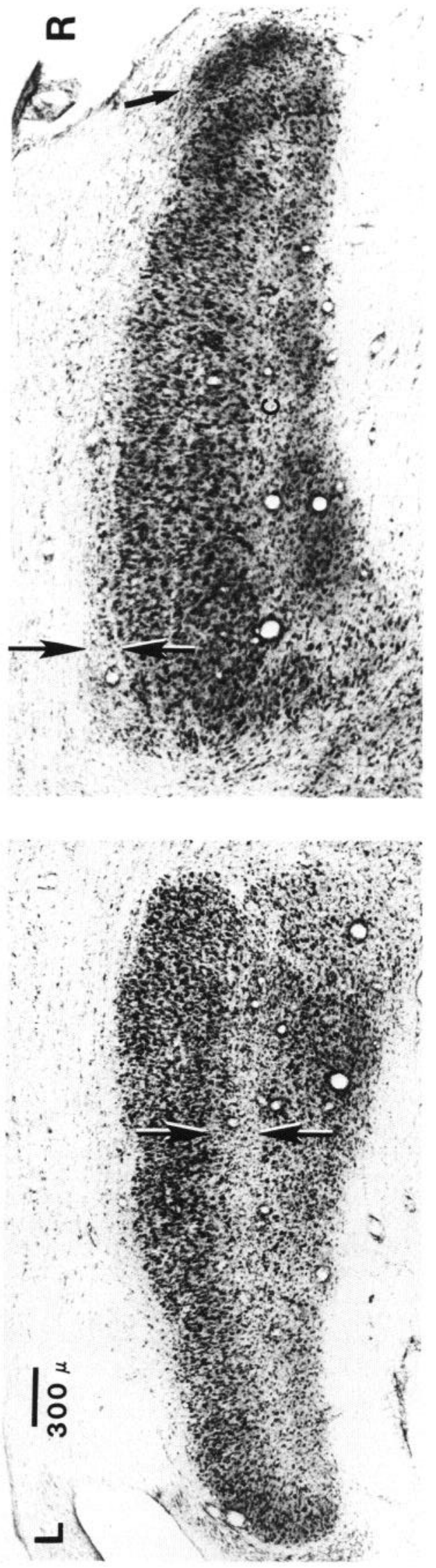

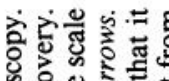

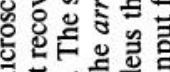

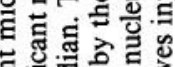

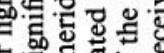

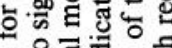

을 젼.

चี

은월

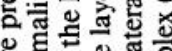

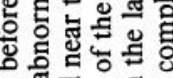

웡흥 ․ㅖㅇ

政

ㄴㅇㅇ.

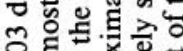

त्रे 믈

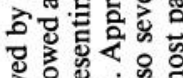

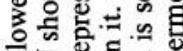

흔원동

डी 3 ह

등월

ब。ำ

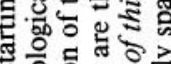

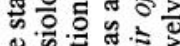

可

ठั่

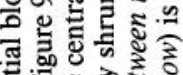

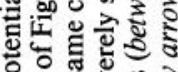

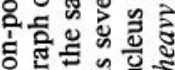

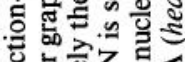

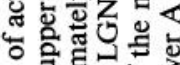

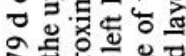

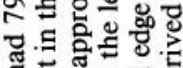

击 $\Xi$. .

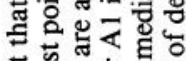

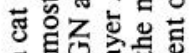

영

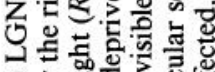

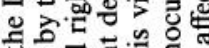

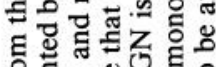

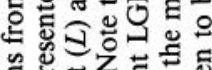

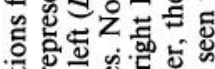

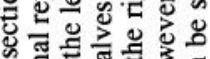

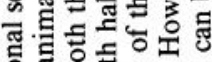

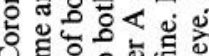

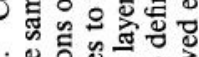

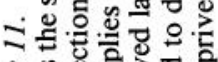

능

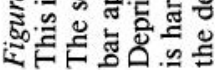




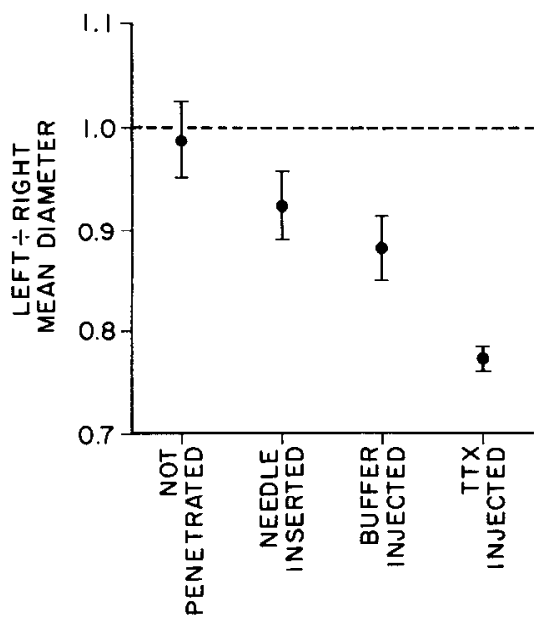

Figure 12. Average diameter of a population of alpha-cells in the deprived eye, divided by the average diameter of a similar population in the normal eye of kittens that received various treatments. A value of 1.0 indicates no ganglion cell body shrinkage in the deprived eye; values of less than 1.0 indicate shrinkage in the deprived eye. Number of animals used: Not Penetrated, $n=2$; Needle Inserted, $n=2$; Buffer Injected, $n=4$; TTX Injected, $n=3$. All animals were treated for approximately 8 weeks from birth, with no recovery period. Bars show SEM. Both needle insertion alone and buffer injection caused about $10 \%$ shrinkage, whereas TTX injection caused about $23 \%$ shrinkage. The values for the Needle Inserted and the Buffer Injected animals are not significantly different $(p>0.4 ; t$ test) and are combined (mean $=0.894 \pm$ $0.023 \mathrm{SEM}$ ) in the significance tests noted next. All of the following means show significant differences ( $t$ test): Needle Inserted plus Buffer Injected versus Not Penetrated $(p<0.05)$; Needle Inserted plus Buffer Injected versus TTX Injected $(p<0.01)$; TTX Injected versus Not Penetrated $(p<0.001)$.

istic large size, which makes their identification unambiguous (Stonc, 1978; Wässle et al., 1975). However, qualitative inspection showed that they were not the only cells in the ganglion cell layer to be affected by the TTX treatment. Alpha-cells were measured in the same region of the retina in all of the eyes studied. This was done in the superior, nasal retina at a point $3 \mathrm{~mm}$ from the area centralis along an axis at an angle of $45^{\circ}$ to the visual streak. For each retina, soma areas were measured for at least 30 cells.

Initial control experiments showed that ganglion cell somas were shrunken in kittens that had received injections of only the citrate buffer vehicle solution without TTX. Thus, we did a series of further control experiments. One set of animals was anesthetized and their conjunctivae were cleared every other day, exactly as if they would be injected, but the injection needle was only pressed against the side of their eye for $30 \mathrm{sec}$, without penetration. Another group of control animals was treated the same way except that the injection needle penetrated into their eye without any substance being injected. TTX treatment of the experimental animals was started within the first two postnatal days and continued until they were sacrificed at 8 weeks of age.

In each animal the average diameter of the cells measured in the injected eye was divided by the average cell diameter in the normal eye. Thus, a ratio of 1.0 represents no shrinkage, while ratios less than 1.0 indicate cell body shrinkage in the treated eyes. These ratios were averaged for each different group of animals. Figure 12 shows the results of these measurements. The alpha-cells in the retinas not penetrated by the needle were normal in size. The cells in the eyes that were penetrated, as well as those that received buffer solution, were shrunken by about $10 \%$. The alpha-cells in the eyes that received TTX treatment were more severely shrunken, by about $23 \%$.

We looked for ganglion cell loss, again studying only alphacells. We first examined the retinas for overall changes in area that would affect cell density measurements and found that the retinas of TTX-injected eyes were the same overall size as those of the uninjected eye. This comparison was made pairwise, between eyes of the same animal, for 14 animals that had been treated with TTX for various times and then allowed to recover for various periods before retinal fixation. Then, a $1 \mathrm{~mm}^{2}$ region was defined, located at the same place on the retina used for the measurements described above, and the number of alphacells within this region counted. The number of cells counted in the injected eye was subtracted from those counted in the normal eye. For the 14 animals, the average difference was $0.86 \pm 1.24$ (SEM) cells, out of the average of 34 found in the region counted. Thus, although TTX resulted in cell soma shrinkage, there was no obvious ganglion cell loss.

\section{Discussion}

These experiments have demonstrated that when retinal ganglion cell firing is totally silenced in young kittens, the axon terminals of these cells develop abnormal patterns of segregation onto their target cells throughout the LGN, including the MIN. There is simultaneous input to individual LGN cells by ONand OFF-center ganglion cells, by $\mathrm{X}$ - and $\mathrm{Y}$-type ganglion cells, and from both eyes. Such mixing of ON and OFF inputs is never seen in normal cats, and the proportion of cells with $\mathrm{X}$ and $\mathrm{Y}$ inputs and of binocular cells is much lower in normal animals than in those that have undergone action-potential blockade. A pattern of abnormal inputs is also shown by the large, sometimes elongated receptive fields of LGN cells, which often display hot spots; a likely explanation of these properties is that the LGN cells are receiving inputs from a group of ganglion cells that is more spatially extended than is normal.

The findings that the nondeprived LGN layers of TTX-injected animals are normal, and that the sham-injected kittens showed no LGN abnormalities, confirm that action-potential blockade itself, and not some generalized systemic effect, is the cause of the LGN abnormalitics wc have scen. Also, we have carried out preliminary experiments in kittens that received binocular TTX injections from birth and have found ON-OFF cells throughout their LGN A layers. This shows that the ONOFF cells found in the monocularly injected animals are not simply the result of some form of competition between the normal and TTX-injected eye.

The presence of ON-OFF type LGN cells has never been reported to result from any other form of visual deprivation, such as monocular lid-suturing or dark-rearing (Kratz, 1982; Movshon and van Sluyters, 1981; Mower et al., 1981; Sherman and Spear, 1982). Our monocular-lid-sutured control experiment, using the same tests as those used for TTX-injected animals, is consistent with this. A fundamental difference between other types of visual deprivation and action-potential blockade is that ganglion cells have significant firing rates even in lidsutured eyes or in animals kept in the dark (Barlow et al., 1957; Burke and Hayhow, 1968; Eysel et al., 1979; Mastronarde, 1983a, b).

At birth, most if not all kitten LGN neurons are present, and all ganglion cell axons have reached the LGN and have segregated almost fully to their proper layers, in appropriate retinotopic order (Elgeti et al., 1976; Kalil, 1978; Richards and Kalil, 1974; Shatz, 1983), although much LGN synaptic development has yet to occur (Cragg, 1975; Kalil, 1978, 1980; Kalil and Scott, 1979, 1981; Winfield and Powell, 1980; Winfield et al., 1980). Action-potential blockade does not seem to affect development that has already occurred. For example, the retinotopic map is not disrupted. Similarly, in kittens in which the TTX treatment does not start until about $21 \mathrm{~d}$ of age, the normal pattern of inputs to LGN cells that has developed by about 3 weeks postnatal is not reversed by the subsequent TTX treatment. Rather, it appears that the synaptic development that takes place during 
the first 3 weeks and leads to input segregation requires the firing of ganglion cell afferents in order to occur properly.

\section{Controls}

We have inferred underlying anatomical connections from electrophysiological examinations of receptive fields. That is, we suggest that LGN ON-OFF cells are receiving monosynaptic excitatory inputs from both $\mathrm{ON}$ - and OFF-center ganglion cells, and that similar considerations apply to the mixed $X-Y$ and binocular LGN cells. In two cases we were able to prove this directly for $\mathrm{ON}$ and $\mathrm{OFF}$ inputs, in a simultaneous retina and LGN recording experiment. This sample is small, mainly for technical reasons. However, the various controls involving manipulation of the visual stimulus, and electrophysiological study of ganglion cells in the deprived eye, support the generality of our interpretation.

Sillito and Kemp (1983) have shown that when the GABA antagonist bicuculline is iontophoresed onto normal cat LGN cells there is a marked decrease of surround antagonism. Presumably GABA-mediated inhibition is blocked. When they applied bicuculline during the presentation of an annular visual stimulus centered on the receptive field, the same cell gave both ON and OFF responses; that is, both center and surround responses. Thus, we must consider the possibility that inhibitory circuitry in the deprived LGN layers of the TTX-treated kittens was affected in such a way as to yield apparently ON-OFF-type receptive fields, even though the LGN cells had excitatory inputs of only one center type. A number of lines of evidence argue against this interpretation. First, an annular stimulus is especially appropriate for eliciting surround responses. We used a spot stimulus, not an annular stimulus, and often small spots could readily elicit the ON-OFF responses. Second, the majority of cells reported by Sillito and Kemp had very unequal responses at $\mathrm{ON}$ and $\mathrm{OFF}$, whereas most of the ON-OFF cells we recorded did not give substantively larger responses at one phase than at the other. Third, the surround responses elicited in the presence of bicuculline often had a significantly longer latency than the center responses, whereas the latencies for both responses were usually equal in the deprived laycr ON-OFF cells. These points, taken together with the direct evidence of the dual-recording experiments, strongly suggest that disruption of inhibitory circuitry is not the main basis of the ON-OFF cells we found.

\section{Susceptibility and recovery}

The later in the first 3 postnatal weeks that action-potential blockade was started, the less severe were its effects. Apparently, normal development that is going on during this period is complete enough by 3 weeks to be irreversible. This time precedes the cortical "critical period," which begins by the third to fourth postnatal week (Movshon and van Sluyters, 1982; Sherman and Spear, 1982). It is not surprising that basic geniculate development should occur before cortical development.

Although the normal development that can be affected by action-potential blockade occurs in the first 3 weeks, the recovery experiments shown in Figure 9 demonstrate that at least some normal development can occur well after 3 weeks postnatal. Long-term TTX treatment seemed to preclude subsequent recovery; however, it is not clear that this is entirely due to a loss of "plasticity" in the LGN. Since the action-potential blockade is monocular, the deprived relay cells in the LGN are outcompeted by the other eye at the level of the visual cortex (Sherman et al., 1974). The inability to recover in the LGN may be secondary to this cortical loss; binocular TTX treatment is needed to assess this possibility. The fact that the animals treated with TTX for only 3 weeks, prior to the cortical critical period, regained full normality lends some support to this idea.

The animals treated for only 3 weeks are interesting in that all of the cells in their deprived LGN layers were not ON-OFF, even at the earliest times during the return of action potentials. As noted, it is possible that some of the ON- or OFF-center cells recorded in the LGN were the artifactual result of uneven ganglion cell recovery. However, it is also possible that at 3 weeks the LGN retains the capacity to reorganize very quickly, once the ganglion cells are allowed to fire. An alternative explanation is that action-potential blockade results in ON-OFF cells in the LGN by causing abnormal synaptic reorganization, and that 3 weeks is not long enough for this process to reach its conclusion.

\section{Anatomical effects}

$L G N$. Prolonged retinal action-potential blockade caused severe, irreversible shrinkage in the deprived LGN layers. This is most likely a secondary result of unequal competition at the cortical level between relay cells from the normal and deprived LGN layers (Sherman et al., 1974). This interpretation is supported by the fact that shrinkage is not as severe in the deprived monocular segment. Also, in preliminary experiments in which both eyes were injected with TTX from birth, there was no substantive layer shrinkage in the LGN.

The shrinkage that results from our monocular TTX treatment differs from the effects that have been reported in adult cats and 7-week-old kittens after a week of action-potential blockade (Kupperman and Kasamatsu, 1983). In those animals, there was $30 \%$ shrinkage of cell bodies in the deprived LGN layers that was entirely reversible, and that was not accompanied by obvious cell loss. It has also been reported that 1-6 weeks of monocular action-potential blockade in the adult cat causes a reversible decrease in the cytochrome oxidase activity in the LGN layers projected to by the treated eye (Wong-Riley and Riley, 1983). Thus, it is clear that while action-potential deprivation of ganglion cells has some reversible metabolic effects on cells in the LGN, these are different from the irreversible changes we have found.

Simple inspection of sections such as those in Figure 11 showed that there was cell loss in the deprived layers. This was especially evident in the more lateral binocular portions of deprived layer A. It is possible that this is due to cell death in the LGN. However, another possibility, suggested by the increased thickness of the normal layers, is that cells of the deprived laycrs have become innervated by inputs from the normal eye and have become part of the adjacent, normal layer. This seems especially likely for the binocular cells.

Retina. It is unclear why ganglion cell somas were affected by the injection process itself. Possibly the transient drops in intraocular pressure that must have accompanied each injection, until the needle-hole healed closed, may have played a role. In any case, further shrinkage of ganglion cell somas was caused by the action-potential blockade. This was irreversible, even after long periods of post-TTX recovery. It is possible that the cell body shrinkage is related to decreased terminal arborization in the LGN. The fact that the deprived LGN cells were not as visually responsive as normal is consistent with the possibility that they received fewer synaptic contacts than normal.

We did not observe any obvious change in ganglion cell density as a function of action-potential blockade. This suggests that blockade did not grossly interfere with the normal process of ganglion cell death that occurs postnatally in the kitten $(\mathrm{Ng}$ and Stone, 1982; Williams et al., 1983). However, a retardation of this ganglion cell death, as has been reported in the neonatal hamster after action-potential blockade (Raabe and Finlay, 1984), could produce a transient excess of axons in the deprived LGN layers. Such an excess might then lead to an increase in competition for postsynaptic sites. This, in turn, might produce abnormal mixing of inputs onto individual LGN cells. Extensive counts of axon numbers in the optic nerves of TTX-treated animals would be needed to assess this possibility. 


\section{Young normal animals}

Our search for ON-OFF cells in normal neonatal kittens yielded cells that were only ON- or OFF-center, at all ages examined. This appears to conflict with the results of Daniels et al. (1978), who found cells with both an ON and an OFF response in their receptive field center in young kittens and adult cats. As discussed in more detail elsewhere (Stark and Dubin, in press), there are a number of factors that may account for the difference between their results and ours. Our cells were all characterized with PSTHs. This was done to distinguish excitatory responses from rebound from inhibition, since simply listening to an audio monitor can give a false impression that a response is excitatory and thus that a cell is ON-OFF. Daniels and coworkers did not routinely use histograms to characterize LGN cells; it seems likely that they called a cell ON-OFF irrespective of whether the responses were excitatory or were rebounds from inhibition. Thus, the term "ON-OFF" probably has a different meaning in their work from ours. This distinction is an important one because of the developmental implications of the presence of $\mathrm{ON}-\mathrm{OFF}$ cells in normal young kittens. The suggestion that the characterization method used by Daniels and coworkers is the basis of our differences is supported by the fact that they are the only workers who have reported significant numbers of ONOFF cells in the A layers of adult cats. Another possible explanation of their findings concerns lagged-X type LGN cells (Mastronarde, 1983c). The existence of these cells was not recognized at the time of their study. Such cells give a delayed sustained response to onc phasc of stimulation and an anomalous transient response at the other phase. Thus, lagged-X cells can be mischaracterized as ON-OFF unless other tests are done to identify them.

\section{Receptive field elongation}

At least two possible explanations can be offered for the fact that many receptive fields in the deprived layers were elongated in azimuth (i.e., horizontally), independent of visual field position. It has been shown that axons in the optic tract are better organized by visual field elevation than by azimuth (Mastronarde, 1984). If this organization is refined by sorting processes in the LGN, the more loosely organized azimuth dimension would nced to be corrected more, and thus could be more susceptible to disruption by action-potential blockade. Another explanation is based on the finding by Bowling and Michael (1984) that the axon terminal fields of Y-type ganglion cells are elongated in the anteroposterior direction (vertical visual axis) in the LGN. This may be correlated with the larger magnification factor of the LGN in that direction than in the mediolateral direction. If the effect of action-potential blockade was to cause the $\mathrm{Y}$-type axon terminal fields to be symmetric rather than elongated, and to have indiscriminate connections, the net result would be a tendency for LGN cells receiving Y-type inputs to have horizontally elongated receptive fields.

\section{Synaptic retraction versus sprouting}

There are at least two ways in which action-potential blockade could cause disruption of normal connections in the LGN: (1) At birth, ganglion cell axons could make synapses in the LGN in the basic adultlike pattern, and then sprout inappropriate contacts in the absence of action potentials. (2) Ganglion cell terminals could normally synapse indiscriminately with LGN cells at birth and then reorganize during the first few postnatal weeks - the lack of action potentials could inhibit this reorganization. We explored these possibilities by examining the LGN of very young kittens for the presence of ON-OFF-type cells. That no such cells were found supports the idea that normal segregation of inputs is already present at birth. However, our determination was a functional one, not an anatomical one. Thus, the possibility still remains that subliminal synapses were present that could not be demonstrated by the tests we used. That is, that ON-center LGN cells still retained some contacts from OFF-center ganglion cells (and vice versa), although these contacts were too weak to cause postsynaptic firing. If so, it could be argued that these synapses, which would normally be eliminated, were in some way enhanced by the process of actionpotential blockade, causing the presence of functional ON-OFF cells.

Elimination of excessive inputs to neurons during development has been shown in some systems (Mariani and Changeux, 1981; Purves and Lichtman, 1980) and has been discussed as a developmental principle (Cowan et al., 1984). Failure of the deprived LGN cells to eliminate such conflicting inputs, if they exist, could readily account for our results. This possibility is especially relevant for the binocular cells we found. Although it has been shown anatomically that almost complete segregation of inputs from each eye is present at birth in kittens (Richards and Kalil, 1974; Shatz, 1983), Shatz and Kirkwood (1984) have demonstrated electrophysiologically that about $50 \%$ of cells at kitten LGN layer borders are binocularly drivable at birth. Since few binocular cells exist in adults, it is clear that most of these binocular cells become monocular, presumably through the retraction of one or the other set of inputs. It seems a reasonable speculation that action-potential blockade both inhibits this retraction and stabilizes the inputs from both eyes, given that we too found almost half of the cells at layer borders to be binocular, in TTX-treated kittens. Another possibility is based on the finding that the lack of action potentials from one eye allows translaminar sprouting of axon terminals of the other (Sur et al., 1985). In fact, the development of such inappropriate inputs from the other eye could be caused by sprouting that is not translaminar. Y-type LGN cells normally have dendritic processes that cross laminar boundaries (Friedlander et al., 1981; Guillery, 1966). There is no cvidence that these dendrites normally receive excitatory input in the layer they cross into. However, abnormal excitatory input onto these dendritic regions in that layer might result from the lack of active inputs in the deprived layers.

\section{Possible mechanisms of the role of action potentials}

Action-potential blockade could contribute to the lack of specification of synaptic connections by removing information in the firing patterns of ganglion cells that may be used in the refinement of those connections. Numerous authors have speculated that during development, inputs that fire in synchrony could stabilize each other in such a way as to become common inputs to the same target cell, while at the same time excluding nonsynchronous inputs (Changeux and Danchin, 1976; Constantine-Paton, 1983; Rauschecker and Singer, 1981; Schmidt, 1982; Stent, 1973; Von der Marlsburg and Willshaw, 1981; Willshaw and Von der Marlsburg, 1976). This is a viable possibility in the LGN because Mastronarde $(1983 a, b)$ has shown in the cat that spontaneous firing is correlated in adjacent retinal ganglion cells of the same center sign. For example, ON-center ganglion cells with overlapping receptive fields tend to fire 5$25 \%$ of their spontaneous spikes synchronously. Further, ONand OFF-center ganglion cells with overlapping receptive fields show an actual decrease in synchronous spike firing, below the chance level expected from their firing rates. Action-potential blockade of all firing could remove the possibility of synaptic sorting based on such activity patterns.

A similar consideration could apply to the binocular cells we found. While there is correlated firing of ganglion cells in the same eye, no close synchrony in the spontaneous firing of the two eyes is to be expected. Thus, complete sorting of the inputs from each eye into separate layers could be dependent on firing and be disrupted by action-potential blockade in one eye (Casagrande and Brunso-Bechtold, 1985). 
Finally, cell-cell recognition based on either cell-surface markers or on molecules released at the synaptic terminal could be a factor in the determination of proper synaptic connections in the LGN. It is possible that such substances, if they exist, are not released from silenced axon terminals. This could either be due to the lack of activity or to TTX-blockade interference with axoplasmic flow of glycoproteins (Edwards and Grafstein, 1984; Riccio and Matthews, 1983), which may be necessary for proper development (Edwards and Grafstein, 1983; Riccio and Matthews, 1984).

\section{Comparison with other systems}

It has been shown in a number of systems that activity plays a role in the segregation of terminals belonging to neurons of like function. For example, activity has been implicated in the abolition of polyneuronal innervation of muscle fibers (Benoit and Changeux, 1978; Harris, 1981; Thompson et al., 1979, 1984), and in the reduction of excess innervation in autonomic ganglia (Purves, 1983; Purves and Lichtman, 1980). In each of these systems, it is fibers that are basically of the same functional type that are in competition. Similarly, in the development of ocular dominance stripes in the "three eye" frog tectum (Reh and Constantine-Paton, 1985) or of ocular dominance columns in cat cortex (Stryker, in press; Stryker and Harris, in press), inputs that differ only in terms of the eye they derive from have been shown to sort based on activity. However, there are fundamental anatomical differences between $X$ and $Y$, and between $O N$ and OFF ganglion cells (see reviews by Dowling and Dubin, 1984; Wässle, 1982). It may well be that these differences are mirrored in antigenic or other cell-surface differences that could be used in the determination of proper synaptic contacts. Nonetheless, our work clearly shows that activity also plays a significant role in this process. Thus, our results support the idea that activity is necessary for the normal development of synaptic specificity not only of like but also of different types of inputs.

\section{References}

Archer, S. M., M. W. Dubin, and L. A. Stark (1982) Abnormal development of kitten retino-geniculate connectivity in the absence of action potentials. Science 217: 743-745.

Barlow, H. B., R. Fitzhugh, and S. W. Kuffler (1957) Change of organization in the receptive fields of the cat's retina during dark adaptation. J. Physiol. (Lond.) 137: 338-354.

Benoit, P., and J.-P. Changeux (1978) Consequences of blocking the nerve with a local anaesthetic on the cvolution of multiinncrvation at the regenerating neuromuscular junction of the rat. Brain Res. 149: 89-96.

Boss, V. C., and J. T. Schmidt (1984) Activity and the formation of ocular dominance patches in dually innervated tectum of goldfish. $\mathrm{J}$. Neurosci. 4: 2891-2905.

Bowling, D. A., and C. R. Michael (1984) Terminal patterns of single, physiologically characterized optic tract fibers in the cat's lateral geniculate nucleus. J. Neurosci. 4: 198-216.

Brindley, G. S. (1969) Nerve net models of plausible size that perform many simple learning tasks. Proc. R. Soc. London. [Biol.] 174: 173191.

Burke, W., and W. R. Hayhow (1968) Disuse in the lateral geniculate nucleus of the cat. J. Physiol. (Lond.) 194: 495-519.

Casagrande, V. A., and J. K. Brunso-Bcchtold (1985) Devclopment of lamination in the lateral geniculate nucleus: Critical factors. In Advances in Neural and Behavioral Development, Vol. 1, R. Aslin, ed., pp. 33-78, Ablex, Norwood, NJ.

Changeux, J.-P., and A. Danchin (1976) Selective stabilisation of developing synapses as a mechanism for the specification of neuronal networks. Nature 264: 705-711.

Cleland, B. G., M. W. Dubin, and W. R. Levick (1971) Sustained and transient neurones in the cat's retina and lateral geniculate nucleus. J. Physiol. (Lond.) 217: 473-496.

Constantine-Paton, M. (1983) Position and proximity in the development of maps and stripes. TINS 6: 32-36.

Constantine-Paton, M., and M. I. Law (1978) Eye-specific termination bands in tecta of three-eyed frogs. Science 202: 639-641.
Constantine-Paton, M., and T. Reh (1983) Eye-specific stripes in the tectal lobes of three-eyed frogs are dependent on neural activity. Soc. Neurosci. Abstr. 9: 760.

Cowan, W. M., J. W. Fawcett, D. D. M. O'Leary, and B. B. Stanfield (1984) Regressive events in neurogenesis. Science 225: 1258-1265.

Cragg, B. G. (1975) The development of synapses in the visual system of the cat. J. Comp. Neurol. 160: 147-166.

Daniels, J. D., J. D. Pettigrew, and J. L. Norman (1978) Development of single-neuron responses in kitten's lateral geniculate nucleus. $J$. Neurophysiol. 41: 1373-1393.

Dowling, J. E., and M. W. Dubin (1984) The vertebrate retina. In Handbook of Physiology, The Nervous System, Volume III, Sensory Processes, I. Darien-Smith, ed., pp. 317-339, Williams \& Wilkins, Baltimore.

Dubin, M. W., and B. G. Cleland (1977) Organization of visual inputs to interneurons of lateral geniculate nucleus of the cat. J. Neurophysiol. 40: 410-427.

Edwards, D. L., and B. Grafstein (1983) Intraocular tetrodotoxin in goldfish hinders optic nerve regeneration. Brain Res. 269: 1-14.

Edwards, D. L., and B. Grafstein (1984) Intraocular injection of tetrodotoxin in goldfish decreases fast axonal transport of $\left[{ }^{3} \mathrm{H}\right]$ glucosamine-labeled materials in optic axons. Brain Res. 299: 190-194.

Elgeti, H., R. Elgeti, and K. Fleischhauer (1976) Postnatal growth of the dorsal lateral geniculate nucleus of the cat. Anat. Embryol. 149: 1-13.

Evans, M. H. (1972) Tetrodotoxin, saxitoxin, and related substances: Their applications in neurobiology. Int. Rev. Neurobiol. 15: 83-166.

Eysel, U. Th., O.-J. Grusser, and K.-P Hoffman (1979) Monocular deprivation and the signal transmission by $\mathrm{X}$ - and $\mathrm{Y}$-neurons of the cat lateral geniculate nucleus. Exp. Brain Res. 34: 521-539.

Fawcett, J. W., and D. D. M. O'Leary (1985) The role of electrical activity in the formation of topographic maps in the nervous system. TINS 8: 201-206.

Fawcett, J. W., D. D. M. O'Leary, and W. M. Cowan (1984) Activity and the control of ganglion cell death in the rat retina. Proc. Natl. Acad. Sci. USA 81: 5589-5593.

Friedlander, M. J., C.-S. Lin, L. R. Stanford, and S. M. Sherman (1981) Morphology of functionally identified neurons in lateral geniculate nucleus of the cat. J. Neurosci. 46:80-129.

Griffith, J. S. (1966) A theory of the nature of memory. Nature 211: $1160-1163$.

Guillery, R. W. (1966) A study of golgi preparations from the dorsal lateral geniculate nucleus of the adult cat. J. Comp. Neurol. 128: 2150.

Harris, W. A. (1981) Neural activity and development. Annu. Rev. Physiol. 43: 689-710.

Hebb, D. O. (1949) The Organization of Behavior, Wiley, New York.

Hochstein, S., and R. M. Shapley (1976) Quantitative analysis of retinal ganglion cell classifications. J. Physiol. (Lond.) 262: 237-264.

Hughes, A. (1975) A quantitative analysis of the cat retinal ganglion cell topography. J. Comp. Neurol. 163: 107-128.

Kalil, R. (1978) Development of the dorsal lateral geniculate nucleus in the cat. J. Comp. Neurol. 182: 265-292.

Kalil, R. (1980) A quantitative study of the effects of monocular enucleation and deprivation on cell growth in the dorsal lateral geniculate nucleus in the cat. J. Comp. Neurol. 189: 483-524.

Kalil, R. E., and G. Scott (1979) Development of retinogeniculate synapses in the dorsal lateral geniculate nucleus of the cat. Soc. Neurosci. Abstr. 5: 791 .

Kalil, R. E., and G. Scott (1981) Development of retinogeniculate synapses following visual deprivation in the cat. Soc. Neurosci. Abstr. 7: 141 .

Kalil, R. E., M. W. Dubin, G. L. Scott, and L. A. Stark (1983) Effects of retinal ganglion cell blockade on the morphological development of retinogeniculate synapses in the cat. Soc. Neurosci. Abstr. 9: 24.

Kalil, R. E., M. W. Dubin, G. L. Scott, and L. A. Stark (1985) Effects of early visual experience and long term recovery on the development of retinogeniculate synapses in cats reared with retinal ganglion cell activity blocked by TTX (ARVO abstracts). Invest. Opthalmal. Vis. Sci. (Suppl.) 26: 287.

Kratz, K. E. (1982) Spatial and temporal sensitivity of lateral geniculate cells in dark-reared cats. Brain Res. 251: 55-63.

Kuppermann, B. D., and T. Kasamatsu (1983) Changes in geniculate cell size following brief monocular blockade of retinal activity in kittens. Nature 306: 465-468. 
Levick, W. R. (1972) Another tungsten microelectrode. Med. Biol Eng. 10: 510-515.

Levy, W. B., J. A. Anderson, and S. Lehmkuhle, eds. (1985) Synaptic Modification, Neuron Selectivity, and Nervous System Organization, Lawrence Erlbaum, Hillsdale, NJ.

Mariani, J., and J.-P. Changeux (1981) Ontogenesis of olivocerebellar relationships. I. Studies by intracellular recordings of the multiple innervation of Purkinje cells by climbing fibers in the developing rat cerebellum. J. Neurosci. 1: 696-702.

Mastronarde, D. N. (1983a) Correlated firing of cat retinal ganglion cells. I. Spontaneously active inputs to $\mathrm{X}$ - and $\mathrm{Y}$-cells. J. Neurophysiol. 49: 303-324.

Mastronarde, D. N. (1983b) Correlated firing of cat retinal ganglion cells. II. Responses of X-and $\mathrm{Y}$-cells to single quantal events. J. Neurophysiol. 49: 325-349.

Mastronarde, D. N. (1983c) Subtypes of X relay cells in cat LGN can be distinguished solely by responses to visual stimuli (ARVO abstracts). Invest. Ophthalmal. Vis. Sci. (Suppl.) 24: 265.

Mastronarde, D. N. (1984) Organization of the cat's optic tract as assessed by single-axon recordings. J. Comp. Neurol. 227: 14-22.

Meyer, R. L. (1982) Tetrodotoxin blocks the formation of ocular dominance columns in goldfish. Science 218: 589-591.

Meyer, R. L. (1983) Tetrodotoxin inhibits the formation of refined retinotopography in goldfish. Dev. Brain Res. 6: 293-298.

Mooney, R. D., M. W. Dubin, and A. C. Rusoff (1979) Interneuron circuits in the lateral geniculate nucleus of monocularly deprived cats. J. Comp. Neurol. 187: 533-544.

Movshon, J. A., and R. C. van Sluyters (1981) Visual neural development. Annu. Rev. Psychol. 32: 477-522.

Mower, G. D., J. L. Burchfiel, and F. H. Duffy (1981) The effects of dark-rearing on the development and plasticity of the lateral geniculate nucleus. Dev. Brain Res. 1: 418-424.

$\mathrm{Ng}, \mathrm{A}$. Y. K., and J. Stone (1982) The optic nerve of the cat: Appearance and loss of axons during normal development. Dev. Brain Res. 5: 263-271.

Norman, J. L. (1974) Development of field responses of the lateral geniculate nucleus in kittens, Ph.D. dissertation, University of California, Riverside.

Purves, D. (1983) Modulation of neuronal competition by postsynaptic geometry in autonomic ganglia. TINS 7: 10-16.

Purves, D., and J. W. Lichtman (1980) Elimination of synapses in the developing nervous system. Science 210: 153-157.

Raabe, J. I., and B. L. Finlay (1984) Retinal impulse blockade by TTX transitorily reduces cell death in the hamster retinal ganglion cell layer. Soc. Neurosci. Abstr. 10: 462.

Rauschecker, J. P., and W. Singer (1981) The effects of early visual experience on the cat's visual cortcx and their possible explanation by Hebb synapses. J. Physiol. (Lond.) 310: 215-239.

Reh, T. A., and M. Constantine-Paton (1985) Eye-specific segregation requires neural activity in three-eyed Rana pipiens. J. Neurosci. 5: 1132-1143.

Riccio, R. V., and M. A. Matthews (1983) Effects of tetrodotoxin upon axoplasmic transport in the developing visual system of the albino rat. Soc. Neurosci. Abstr. 9: 150.

Riccio, R. V., and M. A. Matthews (1984) Intraocular TTX causes synaptic changes in the rat dorsal lateral geniculate nucleus during postnatal development. Soc. Neurosci. Abstr. 10: 461.

Richards, W., and R. Kalil (1974) Dissociation of retinal fibers by degeneration rate. Brain Res. 72: 288-293.

Rusoff, A. C., and M. W. Dubin (1977) Development of receptivefield propertics of retinal ganglion cells in kittens. J. Neurophysiol. 40: 1188-1198.

Sanderson, K. J. (1971) The projection of the visual field to the lateral geniculate and medial interlaminar nuclei in the cat. J. Comp. Neurol. 143: 101-118.

Sanderson, K. J., P. O. Bishop, and I. Darian-Smith (1971) The properties of the binocular receptive fields of lateral geniculate neurons. Exp. Brain Res. 13: 178-207.

Sanes, D. H., and M. Constantine-Paton (1983) Altered activity patterns during development reduce neuronal tuning. Science 221: $1183-$ 1185.

Sanes, D. H., and M. Constantine-Paton (1985) The sharpening of frequency tuning curves requires patterned activity during development in the mouse, Mus musculus. J. Neurosci. 5: 1152-1166.

Schmidt, J. T. (1982) The formation of retinotectal projections. TINS 5: $111-116$.

Schmidt, J. T., and D. L. Edwards (1983) Activity sharpens the map during the regeneration of the retinotectal projection in goldfish. Brain Res. 269: 29-39.

Shatz, C. J. (1983) The prenatal development of the cat's retinogeniculate pathway. J. Neurosci. 3: 482-499.

Shatz, C. J., and P. A. Kirkwood (1984) Prenatal development of functional connections in the cat's retinogeniculate pathway. J. Neurosci. 4: 1378-1397.

Sherman, S. M., and P. D. Spear (1982) Organization of visual pathways in normal and visually deprived cats. Physiol. Rev. 62: 738855.

Sherman, S. M., R. W. Guillery, J. H. Kaas, and K. J. Sanderson (1974) Behavioral, electrophysiological and morphological studies of binocular competition in the development of the geniculo-cortical pathways of cats. J. Comp. Neurol. 158: 1-18.

Sillito, A. M., and J. A. Kemp (1983) The influence of GABAergic inhibitory processes on the receptive field structure of $\mathrm{X}$ and $\mathrm{Y}$ cells in cat dorsal lateral geniculate nucleus (dLGN). Brain Res. 277: 6377

Stark, L. A., and M. W. Dubin (in press) Response properties of neurons in the lateral geniculate nucleus of neonatal kittens. Vis. Res.

Stent, G. S. (1973) A physiological mechanism for Hebb's postulate of learning. Proc. Natl. Acad. Sci. USA 70: 997-1001.

Stone, J. (1978) The number and distribution of ganglion cells in the cat's retina. J. Comp. Neurol. 180: 753-772.

Stryker, M. P. (in press) Evidence for a possible role of spontaneous electrical activity in the development of the mammalian visual cortex. In Developmental Neurophysiology, P. Kellaway and D. P. Purpura, eds., Johns Hopkins U. P., Baltimore, MD.

Stryker, M. P., and W. A. Harris (in press) Binocular impulse blockade prevents formation of ocular dominance columns in the cat's visual cortex. J. Neurosci.

Sur, M., P. E. Garraghty, and M. P. Stryker (1985) Morphology of physiologically identified retinogeniculate axons in cats following blockade of retinal impulse activity. Soc. Neurosci. Abstr. 11: 805.

Thompson, W., D. P. Kuffler, and J. K. S. Jansen (1979) The effect of prolonged, reversible block of nerve impulses on the elimination of polyneuronal innervation of new-born rat skeletal muscle fibers. Neuroscience 4: 271-281.

Thompson, W. J., L. A. Sutton, and D. A. Riley (1984) Fibre type composition of single motor units during synapse elimination in neonatal rat soleus muscle. Nature 309: 709-711.

Udin, S. B. (1983) Abnormal visual input leads to development of abnormal axon trajectories in frogs. Nature 301: 336-338.

Von der Marlsburg, C., and D. J. Willshaw (1981) Co-operativity and brain organization. TINS 4: 80-83.

Wässle, $H$. (1982) Morphological types and central projections of ganglion cells in the cat retina. In Progress in Retinal Research, N. Osborne and G. Chader, eds., pp. 125-152, Pergamon, Oxford.

Wässle, H., W. R. Levick, and B. G. Cleland (1975) The distribution of the alpha type of ganglion cells in the cat's retina. J. Comp. Neurol. 159: 419-437.

Williams, R. W., M. J. Bastiani, and L. M. Chalupa (1983) Loss of axons in the cat optic nerve following fetal unilateral enucleation: An electron microscopic analysis. J. Neurosci. 3: 133-144.

Willshaw, D. J., and C. von der Malsburg (1976) How patterned ncural connections can be set up by self-organization. Proc. R. Soc. London [Biol.] 194: 431-445.

Winfield, D. A., and T. P. S. Powell (1980) An electron-microscopical study of the lateral geniculate nucleus in the normal kitten and after eyelid suture. Proc. R. Soc. London [Biol.] 210: 197-210.

Winfield, D. A., R. W. Hiorns, and T. P. S. Powell (1980) A quantitative electron-microscopical study of the postnatal development of the lateral geniculate nucleus in normal kittens and in kittens with evelid suture. Proc. R. Soc. London [Biol.] 210: 21 1-234.

Wong-Riley, M., and D. A. Riley (1983) The effect of impulse blockage on cytochrome oxidase activity in the cat visual system. Brain Res. 261: 185-193. 